\title{
Efficacy and safety of current medications for treating severe and non-severe COVID-19 patients: an updated network meta-analysis of randomized placebo-controlled trials
}

\author{
Qinglin Cheng ${ }^{1,2,{ }^{*}}$, Junfang Chen ${ }^{1,{ }^{*}}$, Qingjun Jia ${ }^{1,{ }^{*}}$, Zijian Fang $^{1,{ }^{*}}$, Gang Zhao ${ }^{1}$ \\ ${ }^{1}$ Hangzhou Center for Disease Control and Prevention, Hangzhou 310021, China \\ ${ }^{2}$ School of Medicine, Hangzhou Normal University, Hangzhou 310021, China \\ ${ }^{*}$ Equal contribution
}

Correspondence to: Gang Zhao; email: zhaohzcdc@sina.com, https://orcid.org/0000-0002-5564-911X

Keywords: efficacy, safety, COVID-19, network meta-analysis, randomized placebo-controlled trials

Received: May 5, $2021 \quad$ Accepted: August 31, $2021 \quad$ Published: September 16, 2021

Copyright: (C) 2021 Cheng et al. This is an open access article distributed under the terms of the Creative Commons Attribution License (CC BY 3.0), which permits unrestricted use, distribution, and reproduction in any medium, provided the original author and source are credited.

\section{ABSTRACT}

Background: Many recent studies have investigated the role of drug interventions for coronavirus disease 2019 (COVID-19) infection. However, an important question has been raised about how to select the effective and secure medications for COVID-19 patients. The aim of this analysis was to assess the efficacy and safety of the various medications available for severe and non-severe COVID-19 patients based on randomized placebocontrolled trials (RPCTs).

Methods: We did an updated network meta-analysis. We searched the databases from inception until July 31, 2021, with no language restrictions. We included RPCTs comparing 49 medications and placebo in the treatment of severe and non-severe patients (aged 18 years or older) with COVID-19 infection. We extracted data on the trial and patient characteristics, and the following primary outcomes: all-cause mortality, the ratios of virological cure, and treatment-emergent adverse events. Odds ratio (OR) and their $95 \%$ confidence interval (Cl) were used as effect estimates.

Results: From 3,869 publications, we included 61 articles related to 73 RPCTs (57 in non-severe COVID-19 patients and 16 in severe COVID-19 patients), comprising 20,680 patients. The mean sample size was 160 (interquartile range 96-393) in this study. The median duration of follow-up drugs intervention was 28 days (interquartile range 21-30). For increase in virological cure, we only found that proxalutamide (OR 9.16, 95\% $\mathrm{Cl} 3.15-18.30$ ), ivermectin (OR 6.33, 95\% Cl 1.22-32.86), and low dosage bamlanivimab (OR 5.29, 95\% Cl 1.12-24.99) seemed to be associated with non-severe COVID-19 patients when compared with placebo, in which proxalutamide seemed to be better than low dosage bamlanivimab (OR 5.69, 95\% $\mathrm{Cl}$ 2.43-17.65). For decrease in all-cause mortality, we found that proxalutamide (OR $0.13,95 \% \mathrm{Cl} 0.09-0.19$ ), imatinib (OR $0.49,95 \% \mathrm{Cl} 0.25-0.96$ ), and baricitinib (OR $0.58,95 \% \mathrm{Cl} 0.42-0.82$ ) seemed to be associated with non-severe COVID-19 patients; however, we only found that immunoglobulin gamma (OR $0.27,95 \% \mathrm{Cl} 0.08-0.89$ ) was related to severe COVID-19 patients when compared with placebo. For change in treatment-emergent adverse events, we only found that sotrovimab (OR $0.21,95 \%$ $\mathrm{Cl}$ 0.13-0.34) was associated with non-severe COVID-19 patients; however, we did not find any medications that presented a statistical difference when compared with placebo among severe COVID-19 patients.

Conclusion: We conclude that marked variations exist in the efficacy and safety of medications between severe and non-severe patients with COVID-19. It seems that monoclonal antibodies (e.g., low dosage bamlanivimab, baricitinib, imatinib, and sotrovimab) are a better choice for treating severe or non-severe COVID-19 patients. Clinical decisions to use preferentially medications should carefully consider the risk-benefit profile based on efficacy and safety of all active interventions in patients with COVID-19 at different levels of infection. 


\section{INTRODUCTION}

Coronavirus disease 2019 (COVID-19) is an unprecedented global life-threatening pandemic. COVID-19 has generated an enormous public health crisis in the world [1]. Though COVID-19 has a relatively low mortality rate, it can cause a highly lethal rate in high-risk patients $[2,3]$. So far, it is unclear how a specific, effective, and secure therapy for severe or non-severe COVID-19 infection is selected [4]. Hence, it is mandatory to identify potential, accurate treatments for patients with severe or non-severe COVID-19 infection [4].

In the past year, pharmacological interventions [e.g., ivermectin, avifavir, doxycycline, sarilumab, bamlanivimab, colchicine, monoclonal antibody, lopinavir/ritonavir (LPV/r), convalescent plasma (CP)] have been widely used in the treatment of COVID-19 patients [4]. A large amount of time and resources have been put into the development of direct-acting antivirals for the SARS-Coronavirus-2 since December 2019 [5]. However, to date, large-scale randomized controlled trials are not only missing due to considering ethics involved but likely also because little time has passed since the emergence of SARS-Coronavirus-2. We did not yet know what drug was the best choice for severe or non-severe COVID-19 patients in clinical practice $[5,6]$.

How to solve the security and efficacy issues in the therapy of COVID-19 infection has become one of the most important challenges [4-6]. Fortunately, network meta-analysis (NMA) can be helpful in assessing the comparative efficacy and safety of multiple interventions, even if they have not been researched head-to-head in randomized controlled trials [7]. Although previous studies of NMA have been carried out on the treatment interventions of COVID-19, most of these studies might have potentially biased results due to lack of standardizing pharmaceutical interventions or the controls [8,9]. For instance, we compared the efficacy and safety for standard of care (SOC), which existed the bias due to the differential SOC of every country (i.e., SOC was not standardized) $[8,9]$. Additionally, we might not verify the pure efficacy and safety of pharmacological interventions due to a positive control drug [10]. There is paucity of head-to-head randomized placebo-controlled trials (RPCTs) comparing different pharmacological interventions for severe or non-severe COVID-19 patients, which can inform clinicians regarding the comparative efficacy and safety of these interventions based on the degree of COVID-19 infection.

To fill this gap, we did an updated network metaanalysis of RPCTs in current medications with severe or non-severe COVID-19 infection, using all available data from published clinical trials. We aimed specifically to compare the efficacy and safety of medications available for severe or non-severe COVID19 patients based on RPCTs.

\section{MATERIALS AND METHODS}

Our study was arranged in line with PRISMA (Preferred Reporting Items for Systematic Reviews and MetaAnalyses) guidelines and its extension statement for NMAs [11].

\section{Data source and search strategy}

We searched the relative data for RPCTs of medications recommended for patients with COVID-19 infection in PubMed, Elsevier Science Direct, Cochrane Library, Google Scholar, SpringerLink, MedRxiv, China National Knowledge Infrastructure, and Wanfangdata. The publication date was set from the beginning of 2019 to July 31, 2021, and no language restrictions. Full search strategies were listed in the Supplementary Materials (Appendix 1). We extracted data on RPCTs, patient and therapy drugs characteristics (Supplementary Table 1).

Two investigators (JQJ and FZJ) via the search strategy screened literature and extracted data. We manually reviewed the titles and abstracts to select the potentially relevant articles' abstracts and full-texts systematically and comprehensively. Then we carefully read the fulltexts and selected eligible articles. Finally, we included all comparative RPCTs for the treatment of COVID-19 patients. The PRISMA flow chart is shown in Figure 1.

\section{Selection criteria}

RPCTs, of at least 1 week's duration, including adult patients (aged $\geq 18$ years) with COVID-19 infection who were in accord with the diagnostic guidelines of World Health Organization [12] were eligible for inclusion. All RPCTs studies that estimated the efficacy or safety between pharmacological interventions and COVID-19 infection were considered for inclusion. Studies were ultimately included if they: (a) were a RPCT; (b) were COVID-19 patients aged 18 years and older; (c) reported COVID-19 related therapy methods as a predictor of clinical outcomes (efficacy or safety), including the ratio of virological cure (VC) or/and all-cause mortality (ACM), or/and treatment-emergent adverse events (TEAEs); and (d) reported any one of the following statistics: VC, ACM, and TEAEs, or other statistics that could be converted into a standardized effect size. Studies were excluded if they: (a) were wrong study design or population (i.e., patients with mild to severe or moderate to severe COVID-19 
infections); (b) were duplicated research or not fulltext articles; (c) had no outcomes/drugs of interest; (d) reported the publication types of non-clinical studies, non-randomized controlled trial, review articles, commentaries, guidelines, and meta-analysis; (e) no primary or missing data existed after contacting authors; or (f) had considerable heterogeneity of studies' groups. We resolved any ambiguity through mutual discussion and consensus during selecting eligible studies.

\section{Data extraction and quality assessment}

Two of five investigators (CQL, CJF, FZJ, JQJ and ZG) independently selected eligible studies, reviewed the main data and supplementary materials, extracted the relevant data information from the included RPCTs, and assessed the risk of bias ( $\kappa$ range for interrater reliability $0.81-0.93$ ) by using a standardized form. We extracted the following data from articles that met the criteria: (1) author name (reference); (2) publication year; (3) country/countries of origin; (4) study design; (5) method of COVID-19 testing; (6) patient population; (7) numbers of participants; (8) gender; (9) age; (10) interventions; (11) treatment medication dose; (12) controls; (13) control medication dose; (14) followup time (days); and (15) primary outcomes. One investigator undertook the initial extraction of studies, and another reviewed the extraction. Any discrepancies were resolved by discussion and consultation by a panel of researchers within the review team $(\mathrm{CQL}, \mathrm{CJF}, \mathrm{FZJ}$, JQJ and ZG).

Three investigators (CQL, JQJ and FZJ) assessed the risk of bias for all study designs. We used the Cochrane Risk-of-Bias Tool [13] to evaluate the studies' risk of bias. We estimated the confidence of evidence contributing to each network estimate using the Grading of Recommendations Assessment, Development, and Evaluation [14].

\section{Outcome measures and definitions}

Our primary outcomes were efficacy (ACM and VC) and safety (TEAEs) between the beginning of intervention and end of follow-up. When the ACM for severe or non-severe COVID-19 patients was measured with the proportion of death due to any cause from treatment initiation to end of follow-up. The VC ratio for severe or non-severe COVID-19 infection was defined as the rate of negative reverse transcriptionpolymerase chain reaction result at the end of the study. Additionally, the TEAEs ratio for severe or non-severe COVID-19 patients referred to the proportion of any TEAEs from the beginning to the end of the study. Patients with COVID-19 infection were stratified into two groups [15]: (1) non-severe COVID-19 patients

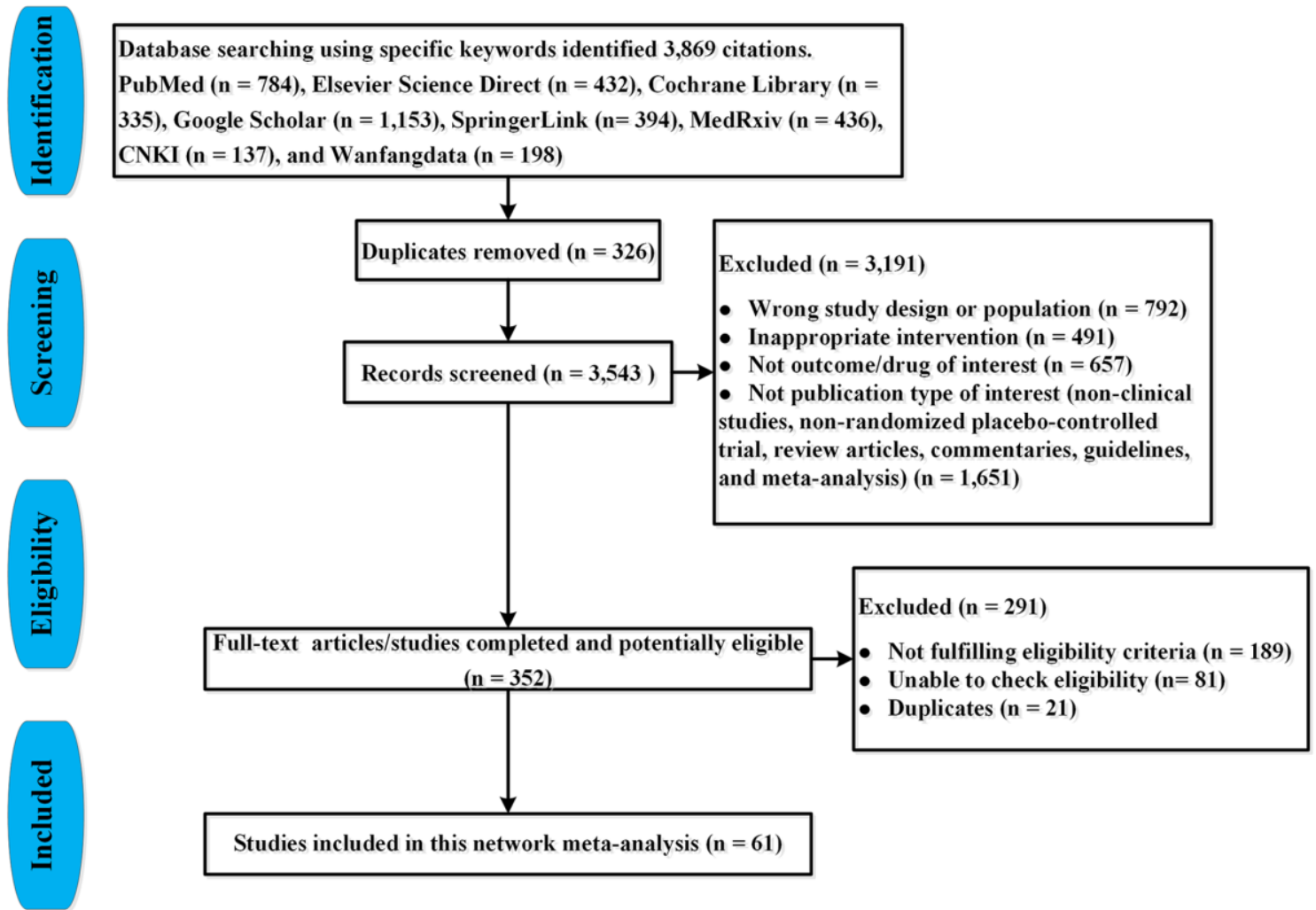

Figure 1. PRISMA flow-chart for study selection. 
including mild and moderate cases (i.e., mild cases represented patients with uncomplicated upper respiratory tract viral infection, and moderate cases represented patients with pneumonia but without need for supplemental oxygen); and (2) severe illness represented patients with fever or suspected respiratory infection, plus one of the following: respiratory rate > 30 breaths $/ \mathrm{min}$, severe respiratory distress, or $\mathrm{SpO} 2 \leq 93 \%$ on room air.

\section{Data synthesis and analysis}

\section{Assessment of the transitivity assumption}

Transitivity is the key underlying assumption of NMA and indirect comparisons. To estimate the transitivity assumption, we investigated the distribution of potential effect modifiers. Possible effect modifiers included multicenter study (MS), duration of study (DS), double blind (DB), crossover design (CD), sample size (SS), industry sponsorship (IS), inequalities in doses (ID), and risk of reported bias (RRB).

\section{Network meta-analysis}

We used STATA statistical software (Version 15, Stata Corporation, and College Station, Texas, USA) and R software version 4.0.4 to perform our Bayesian NMA. Additional details were described in the Supplementary Materials (Appendix 2). Statistical significance was defined as a 2 -sided $P$-value of less than 0.05 .

To describe the comparative efficacy and safety of all medications, we conducted a Bayesian NMA using all available pharmacological regimens. The NMA provided better comparative evidence than conventional meta-analysis due to the merged applying of direct (e.g., head-to-head comparative studies) and indirect evidence (i.e., single arm and non-comparative studies) or different indirect evidence [16]. We calculated summary odds ratio $(\mathrm{OR})$ with $95 \%$ confidence interval $(\mathrm{CI})$ to estimate dichotomous outcomes. The rank of effect estimation for each medication was investigated using the surface under the surface under the cumulative ranking area (SUCRA) curve and mean ranks [17].

\section{Assessment of heterogeneity and inconsistency}

We used the node-splitting method to assess the inconsistency of the model. When Bayesian $P$-value of model was less than 0.05 , it was considered as the existence of significant inconsistency. We also used the $\mathrm{Chi}^{2}$ test and $\mathrm{I}^{2}$ statistics (heterogeneity variance parameter) to estimate the heterogeneity of the NMA, in which the heterogeneity between studies was defined as high if $\mathrm{I}^{2}>50 \%$ and the random-effects model was used. On the contrary, the heterogeneity between studies was estimated as low and the fixed effects mode was used.
We fitted the NMA model by calculating the ranking probabilities after the generation of heterogeneity matrix [7]. Moreover, the small-study effect was estimated by using funnel plots in this NMA [16].

\section{Sensitivity analysis and meta-regression}

We planned a set of subgroup and sensitivity analyses to assess the effect of clinical and study design effect modifiers-e.g., MS, DS, DB, CD, SS, IS, ID, and RRB. The primary outcomes were separately analyzed for severe and non-severe COVID-19 patients as these patients might respond differently to pharmacological interventions.

During the treatment of COVID-19 patients, MS, DS, $\mathrm{DB}, \mathrm{CD}, \mathrm{SS}$, IS, ID, and RRB might influence the data analysis of efficacy and safety. Thus, we investigated whether these covariates were related to change in COVID-19 parameters. We did meta-regressions aiming to examine the relationship between medicationassociated COVID-19 therapy and MS, DS, DB, CD, SS, IS, ID, and RRB.

We used the netmeta package in $\mathrm{R}$ (version 4.0.4) to duplicate NMAs of the primary outcomes.

\section{Availability of data and materials}

All relevant data to the study were included in the article or uploaded as supplementary information. Data is available upon reasonable request.

\section{RESULTS}

\section{Characteristics and quality of included studies}

We identified 3,869 citations through our searches, from which 73 RPCTs (57 in non-severe COVID-19 patients and 16 in severe COVID-19 patients), comprising 20,680 patients were selected. Sixty-one articles (i.e., 46 in nonsevere COVID-19 [18-63], 15 in severe COVID19 infection [64-78]) evaluating 49 different medications or placebo were included in this NMA, in which 12 articles were not yet published in peerreviewed journals (Supplementary Table 1, Figure 1). Supplementary Table 1 summarized the characteristics of included studies. The mean sample size was 160 [interquartile range (IQR) 96-393] in this network analysis. The age of all patients was older than 18 years. The median duration of follow-up drugs intervention was 28 days (IQR 21-30). All 73 RPCTs performed the quality assessment using the Cochrane Risk-of-Bias Tool (Supplementary Tables 2 and 3). Overall, most of the studies were considered to be of good quality with low risk of bias (Figure 2, Supplementary Tables 2 and 3). 


\section{Comparative efficacy and safety of pharmacological interventions}

As can be seen from Figure 3, the network of eligible comparisons for the efficacy and safety of pharmacological interventions. This NMA included 20,680 patients randomly assigned to 146 interventions or controls. In summary, this NMA presented wellconnected nodes. All medications [e.g., $\alpha$-Lipoic acid (ALA), hydroxychloroquine (HCQ), peginterferon lambda (PL), HCQ/azithromycin (HCQ/AZM), LYCoV555, CP, remdesivir, proxalutamide, ivermectin/

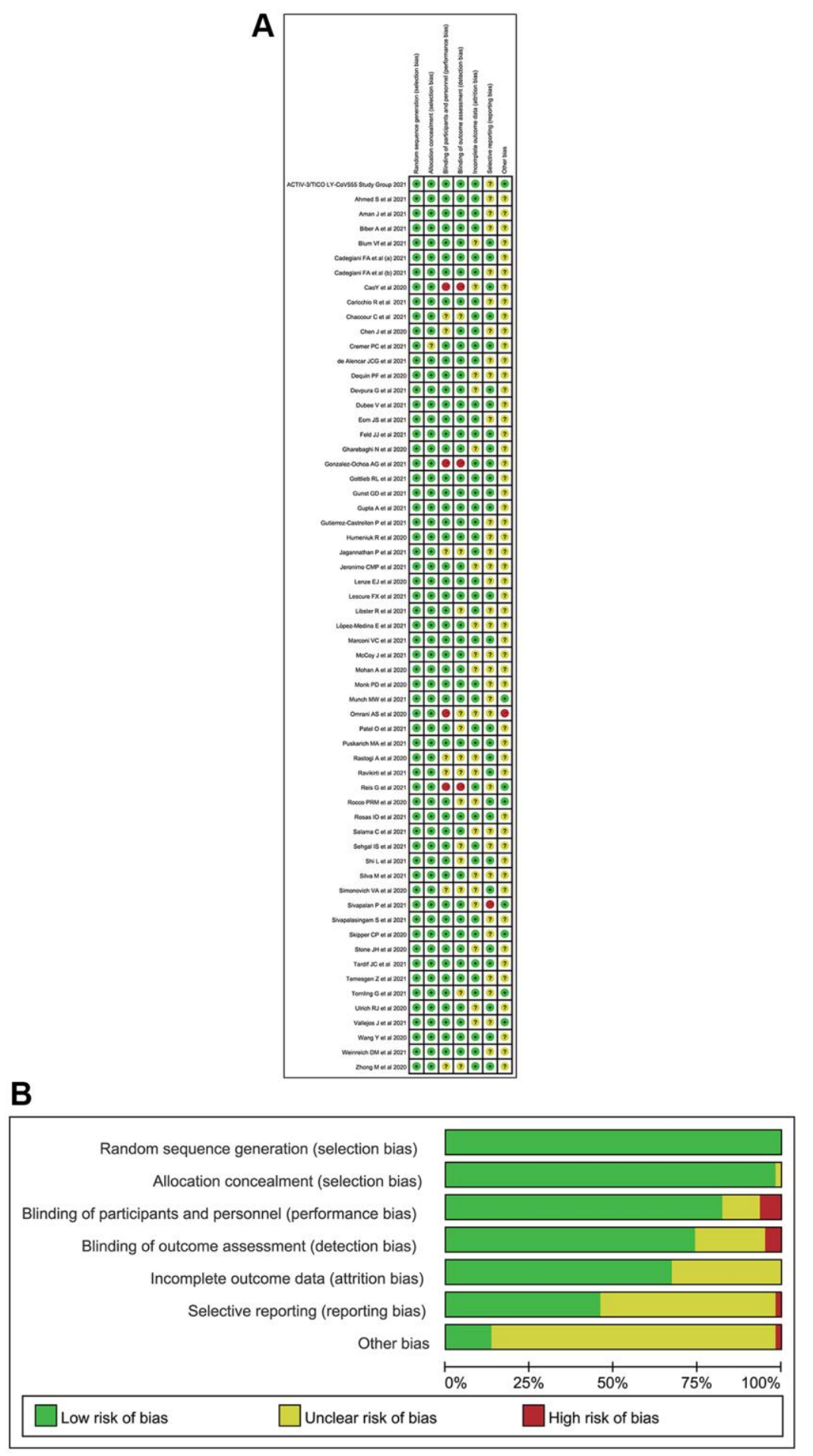

Figure 2. The quality for included randomized placebo-controlled trials. (A) Risk of bias summary (Note: The yellow circle with question mark represents "unclear risk of bias", the red one with minus sign represents "high risk of bias" and the green one with plus sign represents "low risk of bias"). (B) Risk of bias graph. 
doxycycline (IDE), high-dose vitamin D (HDVD), canakinumab, camostat-mesilate, C21, ivermectin, colchicine, high-dose intravenous zinc (HDIVZn), interferon beta (IFN- $\beta$ ), LPV/r, low dosage CT-P59 (LCP), CT-P59 combined (CPC), high dosage CT-P59 (HCP), REGN-COV2, low dosage bamlanivimab (LDB), moderate dosage bamlanivimab (MDB), high dosage bamlanivimab (HDB), MDB/etesevimab, low dosage sarilumab (LS), high dosage sarilumab (HS), sotrovimab, sulodexide, novel probiotic formulation (NPF), losartan, ayurvedic, nitazoxanide, lenzilumab, hydrocortisone, imatinib, ruxolitinib, baricitinib, arbidol, fluvoxamine, immunoglobulin gamma (IG), low dosage ivermectin (LDI), mavrilimumab, methylprednisolone, mycobacterium-w, N-acetylcysteine, tocilizumab, and UC-MSCs] directly connected to placebo (Figure 3).

\section{The rate of virological cure for non-severe COVID- 19 patients}

Twenty-one studies $(N=4,336)$, comprising of 29 RPCTs, contributed to the analysis of VC ratio (Supplementary Table 4). This NMA showed that 18 medications (e.g., arbidol, ayurvedic, CPC, HCP, HCQ, HCQ/AZM, HDB, HDVD, IDE, LCP, LDI, MDB, $\mathrm{MDB} /$ etesevimab, methylprednisolone, nitazoxanide,
PL, REGN-COV2, and remdesivir) were not associated with an increased ratio of $\mathrm{VC}$ compared with placebo. Other medications, such as proxalutamide (OR 9.16, 95\% CI 3.15-18.30), ivermectin (OR 6.33, 95\% CI 1.22-32.86) and LDB (OR 5.29, 95\% CI 1.12-24.99) seemed to significantly increase the ratio of $\mathrm{VC}$ compared with placebo (Figure 4A). Whilst the efficacy of proxalutamide for the $\mathrm{VC}$ was significantly better than LDB (OR 5.69, 95\% CI 2.43-17.65) in patients with non-severe COVID-19 infection. However, no statistical difference for the VC of COVID-19 was found between proxalutamide and ivermectin (OR 11.56, 95\% CI 0.41-28.89). The supplementary (Supplementary Figure 1) presented the ranking of the VC ratio for non-severe COVID-19 patients based on cumulative probability plots and SUCRA. The ranking for non-severe COVID-19 patients with the efficacy of $\mathrm{VC}$ ratio from high to low was as follows: proxalutamide (SUCRA: 92.9\%), ayurvedic (SUCRA: 87.5\%), HDVD (SUCRA: 79.8\%), ivermectin (SUCRA: 77.6\%), LCP (SUCRA: 60.0\%), IDE (SUCRA: 59.8\%), PL (SUCRA: 59.4\%), nitazoxanide (SUCRA: 51.8\%), CPC (SUCRA: 50.5\%), arbidol (SUCRA: 48.8\%), REGN-COV2 (SUCRA: 44.0\%), HCP (SUCRA: 43.3\%), LDI (SUCRA: 42.7\%), HCQ/AZM (SUCRA: 41.1\%), remdesivir (SUCRA: 39.3\%), MDB/etesevimab (SUCRA: 35.7\%), LDB
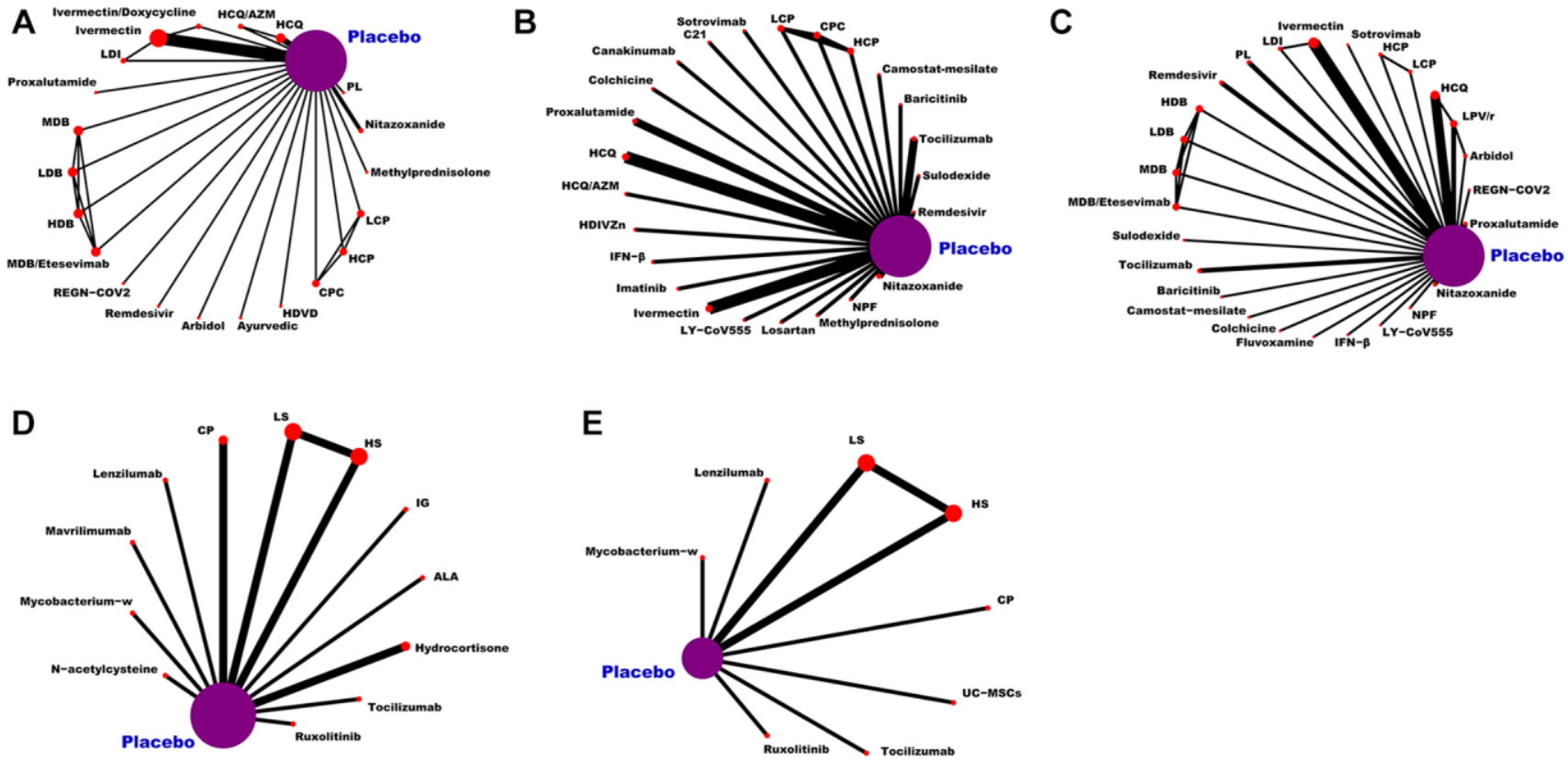

Figure 3. Network plot of eligible comparisons for medications. (A) The VC ratio of non-severe COVID-19 patients. (B) All-cause mortality of non-severe COVID-19 patients. (C) The TEAEs ratio of non-severe COVID-19 patients. (D) All-cause mortality of severe COVID-19 patients. (E) The TEAEs ratio of severe COVID-19 patients. Abbreviations: COVID-19: coronavirus disease 2019; VC: virological cure; TEAEs: treatment-emergent adverse events; PL: peginterferon lambda; LDI: low dosage ivermectin; LPV/r: lopinavir-ritonavir; AZM: azithromycin; HDVD: high-dose vitamin D; HDIVZn: high-dose intravenous zinc: LCP: low dosage CT-P59; HCP: high dosage CT-P59; CPC: CT-P59 combined; HCQ: hydroxychloroquine; LDB: low dosage bamlanivimab; MDB: moderate dosage bamlanivimab; HDB: high dosage bamlanivimab; LS: low dosage sarilumab; HS: high dosage sarilumab; NPF: novel probiotic formulation; CP: convalescent plasma; ALA: $\alpha$-Lipoic acid; IFN- $\beta$ : interferon beta; IG: immunoglobulin gamma. 
(SUCRA: 35.1\%), methylprednisolone (SUCRA: 33.5\%), MDB (SUCRA: 32.4\%), placebo (SUCRA: $31.1 \%$ ), HDB (SUCRA: 30.1\%), and HCQ (SUCRA: 28.4\%) (Supplementary Figure 1).

\section{All-cause mortality for non-severe COVID-19 patients}

For change in ACM, 29 studies compared 24 different medications (7,058 patients) with placebo (6,422 patients) in non-severe COVID-19 patients (Supplementary Table 5). We did not find evidence of ACM decreasing with C21, CPC, camostat-mesilate, canakinumab, colchicine, HCP, HCQ, HCQ/AZM, HDIVZn, IFN- $\beta$, ivermectin, LCP, LY-CoV555, losartan, methylprednisolone, NPF, nitazoxanide, remdesivir, sotrovimab, sulodexide, and tocilizumab when compared with placebo. We found evidence of ACM decreasing with proxalutamide (OR $0.13,95 \%$ CI 0.09 0.19 ), imatinib (OR $0.49,95 \%$ CI $0.25-0.96$ ), and baricitinib (OR 0.58, 95\% CI 0.42-0.82) (Figure 4B). Meanwhile, we found that proxalutamide seemed to be more effective than both imatinib (OR 0.26, 95\% CI $0.12-0.57$ ), and baricitinib (OR 0.22 , 95\% CI $0.13-$ 0.37 ) for reducing the ACM of non-severe COVID-19 patients (Figure 4B). Based on cumulative probability plots and SUCRA, the supplementary (Supplementary Figure 2) presented the ranking for the ACM of medications in non-severe COVID-19 patients. The ranking for the ACM of non-severe COVID-19 patients from high to low was as follows: proxalutamide (SUCRA: 91.4\%), IFN- $\beta$ (SUCRA: 80.6\%), nitazoxanide (SUCRA: 72.4\%), sulodexide (SUCRA: 67.8\%), C21 (SUCRA: 65.9\%), imatinib (SUCRA: 64.7\%), sotrovimab (SUCRA: 63.0\%), baricitinib (SUCRA: 59.2\%), colchicine (SUCRA: 58.0\%), CPC (SUCRA: 53.9\%), canakinumab (SUCRA: 52.4\%), ivermectin (SUCRA: 49.9\%), HCQ (SUCRA: 48.6\%), HDIVZn (SUCRA: 45.8\%), NPF (SUCRA: 43.3\%), LCP (SUCRA: 42.3\%), HCP (SUCRA: 41.4\%), losartan (SUCRA: 41.4\%), camostat-mesilate (SUCRA: 37.0\%), methylprednisolone (SUCRA: 36.8\%), placebo (SUCRA: 33.9\%), remdesivir (SUCRA: 29.7\%), tocilizumab (SUCRA: 26.9\%), HCQ/AZM (SUCRA: 24.0\%), and LY-CoV555 (SUCRA: 19.6\%) (Supplementary Figure 2).

\section{The ratio of treatment-emergent adverse events for non-severe COVID-19 patients}

For change in the ratio of TEAEs, 40 studies compared twenty-six different medications (7,857 patients) with placebo (6,681 patients) in non-severe COVID-19 patients (Supplementary Table 6). In terms of safety, only sotrovimab seemed to be associated with lower the ratio of TEAEs than placebo (OR $0.21,95 \%$ CI $0.13-$ $0.34)$. We analyzed other medications that were not statistically different from one another (Figure 4C). The supplementary (Supplementary Figure 3) presented the ranking for the TEAEs ratio of medications in nonsevere COVID-19 patients according to cumulative probability plots and SUCRA. The ranking for nonsevere COVID-19 patients with the ratio of TEAEs from high to low was as follows: proxalutamide (SUCRA: 98.7\%), REGN-COV2 (SUCRA: 85.6\%), NPF (SUCRA: 80.3\%), MDB/etesevimab (SUCRA: 77.0\%), camostat-mesilate (SUCRA: $73.2 \%$ ), HCP (SUCRA: 62.3\%), HDB (SUCRA: 59.9\%), colchicine (SUCRA: $59.1 \%$ ), ivermectin (SUCRA: $58.7 \%$ ), IFN- $\beta$ (SUCRA: 56.5\%), sotrovimab (SUCRA: 53.1\%), tocilizumab (SUCRA: 52.8\%), nitazoxanide (SUCRA: $52.2 \%$ ), MDB (SUCRA: 50.6\%), LCP (SUCRA: 45.9\%), fluvoxamine (SUCRA: 44.5\%), arbidol (SUCRA: $43.2 \%$ ), LDB (SUCRA: 42.1\%), baricitinib (SUCRA: $40.1 \%$ ), placebo (SUCRA: $39.5 \%$ ), HCQ (SUCRA: 36.6\%), LY-CoV555 (SUCRA: 29.2\%), remdesivir (SUCRA: 29.2\%), LDI (SUCRA: 25.0\%), sulodexide (SUCRA: 23.8\%), PL (SUCRA: 18.8\%), and LPV/r (SUCRA: 11.9\%) (Supplementary Figure 3).

\section{All-cause mortality for severe COVID-19 patients}

Fourteen studies compared 16 different medications (2,008 patients) with placebo (1,081 patients) contributed to this analysis on ACM in severe COVID19 patients (Supplementary Table 7). Compared with placebo, we only found that IG (OR $0.27,95 \%$ CI 0.08-0.89) seemed to be associated with decreased ACM (Figure 5A). However, no statistical difference for the ACM in severe COVID-19 patients was found in other medications (Figure 5A). Based on cumulative probability plots and SUCRA, the supplementary (Supplementary Figure 4) presented the ranking for the ACM of medications in severe COVID-19 patients. The ranking for the ACM of severe COVID-19 patients from high to low was as follows: ALA (SUCRA: 83.0\%), IG (SUCRA: 80.7\%), ruxolitinib (SUCRA: 79.8\%), mavrilimumab (SUCRA: 72.6\%), lenzilumab (SUCRA: 55.3\%), hydrocortisone (SUCRA: 53.8\%), CP (SUCRA: $41.6 \%$ ), mycobacterium-w (SUCRA: 40.8\%), N-acetylcysteine (SUCRA: $32.4 \%$ ), placebo (SUCRA: $31.3 \%$ ), tocilizumab (SUCRA: 30.8\%), LS (SUCRA: 28.6\%), and HS (SUCRA: 19.1\%) (Supplementary Figure 4).

\section{The ratio of treatment-emergent adverse events for severe COVID-19 patients}

A total of 8 studies compared eight different medications (1,316 patients) with placebo (692 patients) formed the evidence network for the TEAEs ratio in severe COVID-19 patients (Supplementary Table 8). Compared with placebo, we found no strong evidence 
of change in the TEAEs ratio with 8 medications for severe COVID-19 patients (Figure 5B). According to cumulative probability plots and SUCRA, the supplementary (Supplementary Figure 5) presented the ranking for the TEAEs ratio of medications in severe COVID-19 patients. The ranking for non-severe

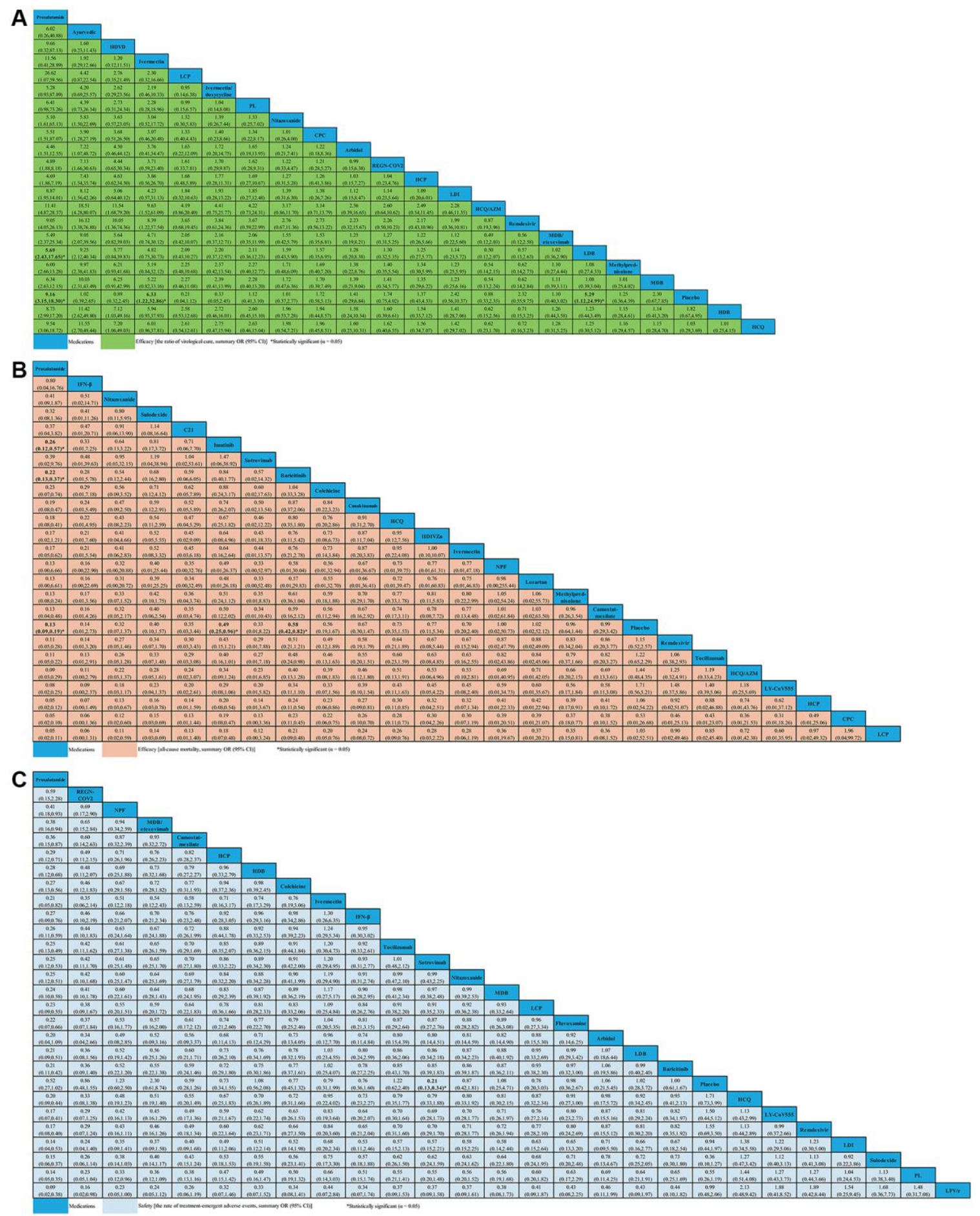

Figure 4. Network meta-analyses of the relative efficacy and safety of medications in non-severe COVID-19 patients. (A) The ratio of virological cure. (B) All-cause mortality. (C) The ratio of treatment-emergent adverse events. Abbreviations: COVID-19: coronavirus disease 2019; OR: odds ratio; Cl: confidence interval; PL: peginterferon lambda; LDI: low dosage ivermectin; LPV/r: lopinavir-ritonavir; AZM: azithromycin; HDVD: high-dose vitamin D; HDIVZn: high-dose intravenous zinc; LCP: low dosage CT-P59; HCP: high dosage CT-P59; CPC: CTP59 combined; HCQ: hydroxychloroquine; LDB: low dosage bamlanivimab; MDB: moderate dosage bamlanivimab; HDB: high dosage bamlanivimab; LS: low dosage sarilumab; HS: high dosage sarilumab; NPF: novel probiotic formulation; CP: convalescent plasma; ALA: $\alpha$ Lipoic acid; IFN- $\beta$ : interferon beta; IG: immunoglobulin gamma. 
COVID-19 patients with the ratio of TEAEs from high to low was as follows: mycobacterium-w (SUCRA: 80.6\%), lenzilumab (SUCRA: 66.1\%), tocilizumab (SUCRA: 60.1\%), UC-MSCs (SUCRA: 53.5\%), ruxolitinib (SUCRA: 53.3\%), placebo (SUCRA: 51.3\%), LS (SUCRA: 35.7\%), CP (SUCRA: 31.3\%), and HS (SUCRA: 30.5\%) (Supplementary Figure 5).

\section{Evaluation of inconsistency}

As shown in Table 1 , based on the $\mathrm{Chi}^{2}$ and $P$ values, we did not find a significant inconsistency for the efficacy and safety outcomes in severe or non-severe patients with COVID-19 infection. In terms of nodesplitting, statistical significance was not shown as the local tests of loop inconsistency (Supplementary Table 9).

\section{Assessment of small study effects}

In general, there was no evidence of small study effects for NMAs based on funnel plot symmetry (Supplementary Figure 6). Direct and indirect evidence showed high agreement throughout NMAs, thus meeting the condition of consistency.

\section{Sensitivity analyses}

We analyzed the possible sources of heterogeneity or inconsistency by using subgroup and meta-regression analyses. Sensitivity analyses showed that most modifiers (such as CD, SS, DS, ID and DB) did not significantly affect the efficacy and safety of medications (Figure 6). However, we found that there was a significant heterogeneity source (i.e., IS) for

A

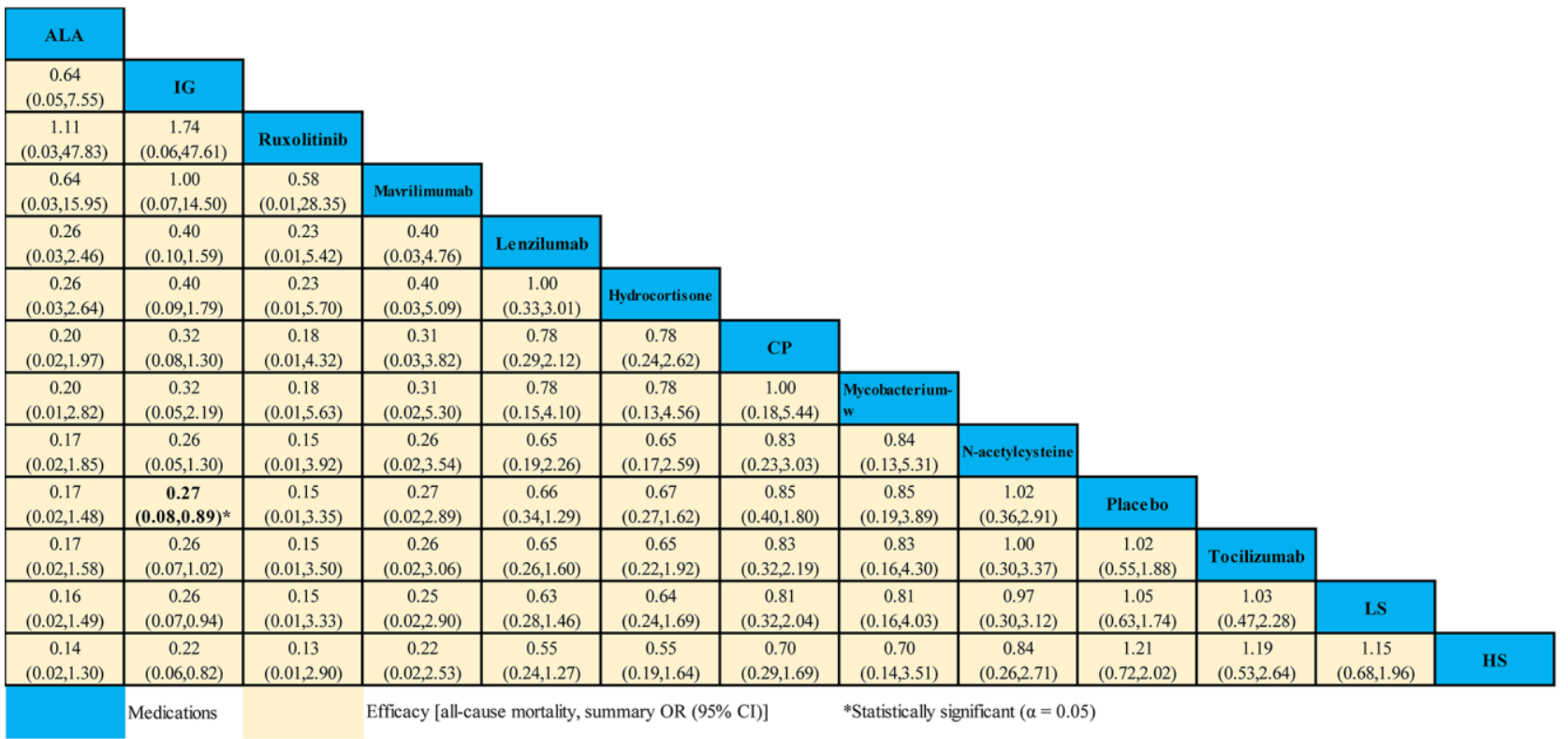

B

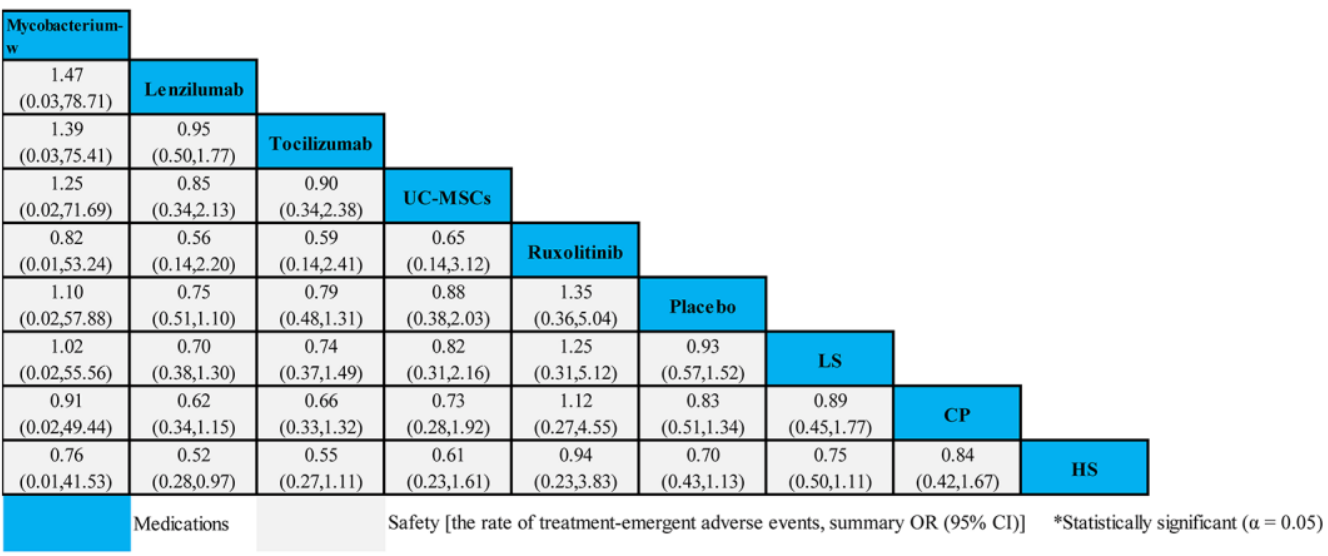

Figure 5. Network meta-analyses of the relative efficacy and safety of medications in severe COVID-19 patients. (A) All-cause mortality. (B) The ratio of treatment-emergent adverse events. Abbreviations: COVID-19: coronavirus disease 2019; OR: odds ratio; Cl: confidence interval; LS: low dosage sarilumab; HS: high dosage sarilumab; CP: convalescent plasma; ALA: $\alpha$-Lipoic acid; IG: immunoglobulin gamma. 
Table 1. The evaluation of inconsistency for the efficacy and safety of medications.

\begin{tabular}{lccc}
\multicolumn{1}{c}{ Network meta-analysis } & $\begin{array}{c}\text { Number of } \\
\text { dimensions }\end{array}$ & Chi $^{2}$ value & $P$ value \\
\hline Non-severe COVID-19 patients & & 3.46 & 0.326 \\
The ratio of virological cure & 21 & 0.98 & 0.996 \\
All-cause mortality & 24 & 1.56 & 0.668 \\
$\quad$ The ratio of treatment-emergent adverse events & 26 & & \\
Severe COVID-19 patients & & 0.02 & 1.000 \\
$\quad$ All-cause mortality & 12 & 0.04 & 1.000 \\
The ratio of treatment-emergent adverse events & 8 & & \\
\hline
\end{tabular}

Abbreviation: COVID-19: coronavirus disease 2019.
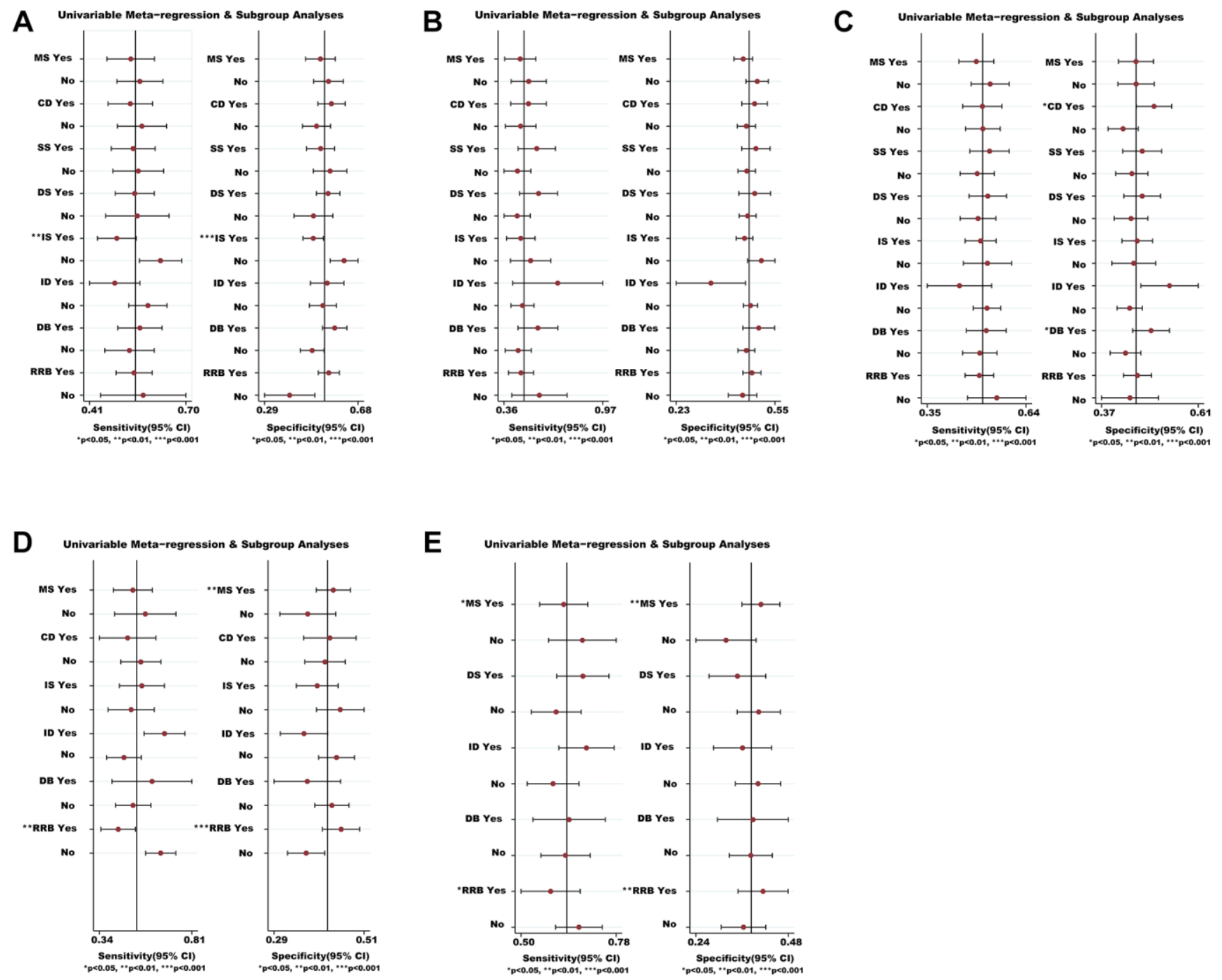

Figure 6. Meta-regression and sensitivity analyses for the efficacy and safety of medications. (A) The VC ratio of non-severe COVID-19 patients. (B) All-cause mortality of non-severe COVID-19 patients. (C) The TEAEs ratio of non-severe COVID-19 patients. (D) Allcause mortality of severe COVID-19 patients. (E) The TEAEs ratio of severe COVID-19 patients. "We conducted meta-regression and sensitivity analyses to estimate the impact of variable for each outcome. The potential modifiers (variables) for meta-regression we select are listed below: MS, DS, DB, CD, SS, IS, ID, and RRB. Abbreviations: COVID-19: coronavirus disease 2019; VC: virological cure; TEAEs: treatmentemergent adverse events; MS: multicenter study; DS: duration of study; DB: double blind; CD: crossover design; SS: sample size; IS: industry sponsorship; ID: inequalities in doses; RRB: risk of reported bias. 
the VC $(P<0.01)$ in non-severe COVID-19 patients (Figure 6A). We also found that the RRB was the heterogeneity source of ACM for severe COVID19 patients based on sensitivity analysis $(P<0.01)$ (Figure 6D). Whilst the MS and RRB seemed to be associated with the TEAEs ratio of severe COVID-19 patients $(P<0.05)$ (Figure 6E).

Finally, we duplicated NMAs of the primary outcomes, which was consistent with the present findings using the netmeta package of $\mathrm{R}$ software.

\section{DISCUSSION}

Previous studies might be biased because pharmacological interventions or the controls were not standardized before performing a meta-analysis [8-10, 79]. To address this shortfall, we performed an updated NMA study based on RPCTs. This updated NMA is based on the studies of 73 RPCTs, which included 20,680 patients randomly assigned to 49 different drug interventions or placebo. The present NMA is essentially more acceptable because it only included the RPCTs (i.e., standardizing the controls), and analyzed the data based on the stratification of COVID-19 infection status (such as severe and nonsevere patients).

\section{Efficacy of current medications in severe or non- severe patients with COVID-19}

We found that medications vary markedly in their efficacy and safety between severe and non-severe COVID-19 infection. Of all the included active interventions, only proxalutamide, ivermectin, and LDB were significantly more efficacious than placebo, in which the efficacy of proxalutamide seemed to be better for the VC in non-severe COVID-19 patients. Prior studies have shown that proxalutamide was effective in eradicating SARS coronavirus [80]. As expected, this finding further supported the work of other studies in this area linking proxalutamide with the viral eradication of SARS-Coronavirus-2. Unfortunately, we were unable to get the relevant data of VC for patients with severe COVID-19 infection in this study. The reason for this is unclear, but maybe researchers think it is not a primary outcome in severe COVID-19 patients. For change in ACM, we found that proxalutamide, imatinib, and baricitinib were more efficacious than placebo for patients with nonsevere COVID-19 infection; however, we only found that IG was associated with decreased ACM in severe COVID-19 patients. Interestingly, for decreasing ACM, we also found that proxalutamide was better than other medications among patients with non-severe COVID-19. Proxalutamide seemed to be the best choice based on efficacy in non-severe COVID-19 patients $[23,24]$.

We found that LDB seemed to be associated with the VC of non-severe COVID-19 patients. However, for higher doses of bamlanivimab we did not find evidence of an effect versus placebo in terms of VC. It seemed that we could not observe bamlanivimab with an apparent dose-response relationship from the $\mathrm{VC}$ of non-severe COVID-19 infection. There are several possible explanations for this considerable difference. First, bamlanivimab with higher doses might be detrimental to innate immune regulation and VC [81]. Second, those higher doses of bamlanivimab might unfavorably change the balance between regulatory T cells and Th17 cells [82-84]. Consistent with the literature [85], this research found that ivermectin was effective in patients with non-severe COVID-19. Thus, we suggested that ivermectin might be a better choice for the treatment of non-severe COVID-19 infection.

Further, our NMA identified that IG, proxalutamide, baricitinib, and imatinib were beneficial to the outcome of COVID-19 infection based on ACM. We suggested that IG might be a choice in the treatment of severe COVID-19 patients, and proxalutamide, baricitinib, and imatinib should be used for the therapy of nonsevere COVID-19 patients. If so, perhaps patients and clinicians should carefully balance the risk-benefit profile to select drug interventions based on efficacy and safety between severe and non-severe patients with COVID-19. However, the interpretation of this result might be limited by insufficient medications selection (i.e., so far, the limited evidence for the therapy of COVID-19 patients) [4].

Undeniably, we should interpret cautiously these findings due to heterogeneity sources including IS and RRB (Figure 6). To verify the value of medications, we need to wait for large-scale RPCTs with target population, sensitive endpoints, and standardized study design among COVID-19 patients. Although previous studies have verified that steroid and auxora, and so on $[86,87]$ were efficacious in clinical practice, we did not include studies of these medications due to the inclusion criterion of RPCTs. Additionally, to identify our findings, further studies need to be conducted by using a stratified analysis based on the reference of different controls.

\section{Safety of current medications in severe or non- severe patients with COVID-19}

As shown in Figures 4 and 5, we only found that sotrovimab was associated with a decrease in TEAEs for non-severe COVID-19 patients when compared with 
placebo; however, for all medications we did not find evidence of a safety versus placebo in terms of TEAEs among severe COVID-19 patients. Curiously, previous studies have indicated that some of the drugs were shown to perform better than placebo on safety: for instance, when compared with placebo, CP, tocilizumab, and ruxolitinib led to reductions in TEAEs in severe COVID-19 patients [88-90]. A possible explanation for this was that we did not include sufficient data in this network analysis. Of note, according to the result of sensitivity analysis, the present finding may need further verification. Therefore, statistical indications of clinical superiority in this study required careful interpretation.

\section{Limitations}

Our analysis had some limitations. First, despite attempts made to include all available RPCTs, we were not able to exclude the possibility of missing data. Second, we only extracted three types of endpoints in the published data. We did not analyze other important outcomes (e.g., discharge ratio and intensive care unit admission). Although we tried to collect better indicators, most studies did not indicate the definition of biological and clinical outcomes. Third, we analyzed only pooled treatment effects and were unable to investigate potentially important clinical and demographic modifiers of treatment response at the individual patient level (i.e., age, sex, severity of symptoms, and duration of illness). Fourth, this NMA did not include unpublished data. Additionally, some nodes in our NMA included only a few trials. The sample size of the actual head-to-head RPCTs was small. Hence, we frequently analyzed their efficacy and safety in different drug interventions through indirect comparisons. Fifth, our study only acute efficacy/adverse events were examined and that more data on potential long-term effects were needed. Moreover, the CIs of effect size estimates were relatively wide, which might affect the reliability of our findings in this NMA. Finally, we found the statistical heterogeneousness in this NMA based on sensitivity analyses. For example, IS, MS, and RRB might conceal or exaggerate the effect size of this NMA. Further research should be undertaken to control these confounding factors.

\section{CONCLUSIONS}

In conclusion, marked variations exist in the efficacy and safety of medications between severe and nonsevere patients with COVID-19. Compared with placebo, of all the included active interventions, only proxalutamide, ivermectin, and LDB might be more efficacious than placebo for the $\mathrm{VC}$ ratio in non-severe
COVID-19 patients; however, we were not able to get the relevant data of VC for severe COVID-19 patients in this NMA. We found that proxalutamide, imatinib, and baricitinib might be associated with the decrease of ACM among non-severe COVID-19 patients; however, for decrease in ACM, we only verified that IG might be related to severe COVID-19 infection. Among them, proxalutamide seemed to be a good choice for the therapy of COVID-19. Based on safety, we suggested that sotrovimab might benefit the treatment of nonsevere COVID-19 patients; however, for change in TEAEs, the difference was not found in all included medications from severe COVID-19 patients.

Notwithstanding these limitations, the findings from this NMA may represent a more comprehensive analysis of the available evidence. It seems that monoclonal antibodies (e.g., LDB, baricitinib, imatinib, and sotrovimab) are a better choice for treating severe or non-severe COVID-19 patients. However, clinical decisions to use preferentially medications should carefully consider the risk-benefit profile based on efficacy and safety of all active interventions in patients with COVID-19 at different levels of infection. Treatment guidelines should be updated to reflect differences in the degree of infection, but the selection of the treatment intervention should be made on a caseby-case basis, considering the clinical circumstances and preferences of patients and clinicians. We hope that these findings will assist in shared decision making between patients and their clinicians. To be sure, more large-scale RPCTs and big data analysis should be collaborated and performed for the treatment of COVID-19 infection. Thus, the prevention and therapy of COVID-19 is set to change for better in the future.

\section{Abbreviations}

COVID-19: coronavirus disease 2019; LPV/r: lopinavir-ritonavir; CP: convalescent plasma; NMA: network meta-analysis; RPCTs: randomized placebocontrolled trials; ACM: all-cause mortality; VC: virological cure; TEAEs: treatment-emergent adverse events; OR: odds ratio; CI: confidence interval; SOC: standard of care; SUCRA: surface under the cumulative ranking area; MS: multicenter study; DS: duration of study; DB: double blind; CD: crossover design; SS: sample size; IS: industry sponsorship; ID: inequalities in doses; RRB: risk of reported bias; IQR: interquartile range; ALA: $\alpha$-Lipoic acid; HCQ: hydroxychloroquine; PL: peginterferon lambda; AZM: azithromycin; IDE: ivermectin/doxycycline; HDVD: high-dose vitamin D; HDIVZn: high-dose intravenous zinc; IFN- $\beta$ : interferon beta; HCP: high dosage CT-P59; LCP: low dosage CT-P59; CPC: CT-P59 combined; LDB: low dosage bamlanivimab; MDB: moderate dosage bamlanivimab; 
HDB: high dosage bamlanivimab; LS: low dosage sarilumab; HS: high dosage sarilumab; NPF: novel probiotic formulation; IG: immunoglobulin gamma; LDI: low dosage ivermectin.

\section{AUTHOR CONTRIBUTIONS}

CQL and ZG had full access to all of the data in the study. CQL takes responsibility for the integrity of the data, the accuracy of the data analysis, and the final decision to submit for publication. CQL, JQJ, CJF, and FZJ contributed to the study concept and design. CQL, ZG, JQJ, FZJ, and CJF contributed to data acquisition, analysis, and interpretation. CQL and ZG drafted the manuscript. CQL and CJF did statistical analysis. CQL obtained funding. JQJ, CJF, and FZJ contributed to administrative, technical, or material support.

\section{ACKNOWLEDGMENTS}

We thank all study authors who responded to our data requests. We also thank the numerous researchers who sent information for our previous reviews on which this report was built. We thank WL for help in the literature search, CJF for help with study screening and JQJ, XL and FZJ for help with data extraction.

\section{CONFLICTS OF INTEREST}

The authors declare no conflicts of interest related to this study.

\section{FUNDING}

This work is supported by the Basic Public Welfare Research Project of Zhejiang Province (grant number: LGF21H260007), the Medical Science and Technology Project of Zhejiang Province (grant number: 2021PY065), and Key Medical Discipline construction project (Disinfection and Vector Control) of Hangzhou.

\section{REFERENCES}

1. World Health Organization (WHO). WHO Coronavirus (COVID-19) Dashboard. https://covid19.who.int/

2. Bae S, Kim SR, Kim MN, Shim WJ, Park SM. Impact of cardiovascular disease and risk factors on fatal outcomes in patients with COVID-19 according to age: a systematic review and meta-analysis. Heart. 2021; 107:373-80.

https://doi.org/10.1136/heartjnl-2020-317901 PMID:33334865

3. Balfanz P, Hartmann B, Müller-Wieland D, Kleines M, Häckl D, Kossack N, Kersten A, Cornelissen C, Müller
T, Daher A, Stöhr R, Bickenbach J, Marx G, et al. Early risk markers for severe clinical course and fatal outcome in German patients with COVID-19. PLoS One. 2021; 16:e0246182.

https://doi.org/10.1371/journal.pone.0246182 PMID:33513168

4. Ita K. Coronavirus Disease (COVID-19): Current Status and Prospects for Drug and Vaccine Development. Arch Med Res. 2021; 52:15-24. https://doi.org/10.1016/i.arcmed.2020.09.010 PMID:32950264

5. Peng $\mathrm{Y}$, Tao $\mathrm{H}$, Satyanarayanan SK, Jin K, Su H. A Comprehensive Summary of the Knowledge on COVID-19 Treatment. Aging Dis. 2021; 12:155-91. https://doi.org/10.14336/AD.2020.1124 PMID:33532135

6. Tsang HF, Chan LWC, Cho WCS, Yu ACS, Yim AKY, Chan AKC, Ng LPW, Wong YKE, Pei XM, Li MJW, Wong SC. An update on COVID-19 pandemic: the epidemiology, pathogenesis, prevention and treatment strategies. Expert Rev Anti Infect Ther. 2021; 19:877-88.

https://doi.org/10.1080/14787210.2021.1863146

PMID:33306423

7. Dias S, Caldwell DM. Network meta-analysis explained. Arch Dis Child Fetal Neonatal Ed. 2019; 104:F8-12.

https://doi.org/10.1136/archdischild-2018-315224 PMID:30425115

8. Bartoszko JJ, Siemieniuk RAC, Kum E, Qasim A, Zeraatkar D, Ge L, Han MA, Sadeghirad B, Agarwal A, Agoritsas T, Chu DK, Couban R, Darzi AJ, et al. Prophylaxis against covid-19: living systematic review and network meta-analysis. BMJ. 2021; 373:n949.

https://doi.org/10.1136/bmj.n949 PMID:33903131

9. Kim MS, An MH, Kim WJ, Hwang TH. Comparative efficacy and safety of pharmacological interventions for the treatment of COVID-19: A systematic review and network meta-analysis. PLoS Med. 2020; 17:e1003501.

https://doi.org/10.1371/journal.pmed.1003501 PMID:33378357

10. Pocock SJ, Clayton TC, Stone GW. Design of Major Randomized Trials: Part 3 of a 4-Part Series on Statistics for Clinical Trials. J Am Coll Cardiol. 2015; 66:2757-66.

https://doi.org/10.1016/i.jacc.2015.10.036 PMID:26700838

11. Tricco AC, Lillie E, Zarin W, O'Brien KK, Colquhoun $\mathrm{H}$, Levac D, Moher D, Peters MDJ, Horsley T, Weeks L, Hempel S, AkI EA, Chang C, et al. PRISMA Extension 
for Scoping Reviews (PRISMA-ScR): Checklist and Explanation. Ann Intern Med. 2018; 169:467-73.

https://doi.org/10.7326/M18-0850

PMID: 30178033

12. World Health Organization (WHO). Laboratory testing for coronavirus disease (COVID-19) in suspected human cases: interim guidance, 19 March 2020. https://apps.who.int/iris/bitstream/handle/10665/ 331501/WHO-COVID-19-laboratory-2020.5-eng.pdf

13. Minozzi S, Cinquini M, Gianola S, Gonzalez-Lorenzo $M$, Banzi R. The revised Cochrane risk of bias tool for randomized trials (RoB 2) showed low interrater reliability and challenges in its application. J Clin Epidemiol. 2020; 126:37-44.

https://doi.org/10.1016/i.jclinepi.2020.06.015 PMID: $\underline{32562833}$

14. GRADE Working Group. Grading of recommendations assessment, development and evaluation. The GRADE Working Group. 2017. https://www.gradeworkinggroup.org

15. World Health Organization. Clinical Management of Severe Acute Respiratory Infection (SARI) When COVID-19 Disease Is Suspected Interim Guidance. 2020. https://apps.who.int/iris/bitstream/handle/10665/ 331446/WHO-2019-nCoV-clinical-2020.4eng.pdf?sequence $=1 \&$ isAllowed $=y$

16. Cipriani A, Higgins JP, Geddes JR, Salanti G. Conceptual and technical challenges in network meta-analysis. Ann Intern Med. 2013; 159:130-37.

https://doi.org/10.7326/0003-4819-159-2201307160-00008

PMID:23856683

17. Mbuagbaw L, Rochwerg B, Jaeschke R, Heels-Andsell D, Alhazzani W, Thabane L, Guyatt GH. Approaches to interpreting and choosing the best treatments in network meta-analyses. Syst Rev. 2017; 6:79. https://doi.org/10.1186/s13643-017-0473-z PMID:28403893

18. Lundgren JD, Grund B, Barkauskas CE, Holland TL, Gottlieb RL, Sandkovsky U, Brown SM, Knowlton KU, Self WH, Files DC, Jain MK, Benfield T, Bowdish ME, et al, and ACTIV-3/TICO LY-CoV555 Study Group. A Neutralizing Monoclonal Antibody for Hospitalized Patients with Covid-19. N Engl J Med. 2021; 384:905-14.

https://doi.org/10.1056/NEJMoa2033130 PMID:33356051

19. Ahmed S, Karim MM, Ross AG, Hossain MS, Clemens JD, Sumiya MK, Phru CS, Rahman M, Zaman K, Somani J, Yasmin R, Hasnat MA, Kabir A, et al. A five-day course of ivermectin for the treatment of COVID-19 may reduce the duration of illness. Int J Infect Dis. 2021; 103:214-16. https://doi.org/10.1016/j.ijid.2020.11.191 PMID: $\underline{3278625}$

20. Aman J, Duijvelaar E, Botros L, Kianzad A, Schippers JR, Smeele PJ, Azhang S, Bartelink IH, Bayoumy AA, Bet PM, Boersma W, Bonta PI, Boomars KAT, et al. Imatinib in patients with severe COVID-19: a randomised, double-blind, placebo-controlled, clinical trial. Lancet Respir Med. 2021; 9:957-68.

https://doi.org/10.1016/S2213-2600(21)00237-X PMID: $\underline{34147142}$

21. Biber A, Mandelboim M, Harmelin G, Lev D, Ram L, Shaham A, Nemet I, Kliker L, Erster O, Schwartz E. Favorable outcome on viral load and culture viability using Ivermectin in early treatment of nonhospitalized patients with mild COVID-19, A doubleblind, randomized placebo-controlled trial. MedRxiv. 2021. https://doi.org/10.1101/2021.05.31.21258081

22. Blum VF, Cimerman $S$, Hunter JR, Tierno $P$, Lacerda A, Soeiro A, Cardoso F, Bellei NC, Maricato J, Mantovani N, Vassao M, Dias D, Galinskas J, et al. Nitazoxanide superiority to placebo to treat moderate COVID-19 - A Pilot prove of concept randomized double-blind clinical trial. EClinicalMedicine. 2021; 37:100981.

https://doi.org/10.1016/i.eclinm.2021.100981 PMID: $\underline{34222847}$

23. Cadegiani FA, Fonseca DN, McCoy J, Zimerman RA, Mirza FN, Correia MN, Barros RN, Onety DC, Israel KCP, de Almeida BG, Guerreiro EO, Medeiros JEM, Nicolau RN, et al. Efficacy of Proxalutamide in Hospitalized COVID-19 Patients: A Randomized, Double-Blind, Placebo-Controlled, Parallel-Design Clinical Trial. MedRxiv. 2021.

https://doi.org/10.1101/2021.06.22.21259318

24. Cadegiani FA, McCoy J, Gustavo Wambier C, VañoGalván S, Shapiro J, Tosti A, Zimerman RA, Goren A. Proxalutamide Significantly Accelerates Viral Clearance and Reduces Time to Clinical Remission in Patients with Mild to Moderate COVID-19: Results from a Randomized, Double-Blinded, PlaceboControlled Trial. Cureus. 2021; 13:e13492.

https://doi.org/10.7759/cureus.13492

PMID:33633920

25. Caricchio R, Abbate A, Gordeev I, Meng J, Hsue PY, Neogi T, Arduino R, Fomina D, Bogdanov R, Stepanenko T, Ruiz-Seco P, Gónzalez-García A, Chen $Y$, et al, and CAN-COVID Investigators. Effect of Canakinumab vs Placebo on Survival Without Invasive Mechanical Ventilation in Patients Hospitalized With Severe COVID-19: A Randomized Clinical Trial. JAMA. 2021; 326:230-39. 
https://doi.org/10.1001/jama.2021.9508

PMID:34283183

26. Chaccour C, Casellas A, Blanco-Di Matteo A, Pineda I, Fernandez-Montero A, Ruiz-Castillo P, Richardson MA, Rodríguez-Mateos $M$, Jordán-Iborra C, Brew J, Carmona-Torre F, Giráldez M, Laso E, et al. The effect of early treatment with ivermectin on viral load, symptoms and humoral response in patients with non-severe COVID-19: A pilot, double-blind, placebo-controlled, randomized clinical trial. EClinicalMedicine. 2021; 32:100720.

https://doi.org/10.1016/i.eclinm.2020.100720 PMID:33495752

27. Chen J, Ling $Y, X i X$, Liu P, Li F, Li T, Shang Z, Wang $M$, Shen $Y$, Lu H. Efficacies of lopinavir/ritonavir and abidol in the treatment of novel coronavirus pneumonia. Chinese Journal of Infectious Diseases. 2020; 38:86-89.

http://rs.yiigle.com/CN311365202002/1188613.htm

28. Devpura G, Tomar BS, Nathiya D, Sharma A, Bhandari D, Haldar S, Balkrishna A, Varshney A. Randomized placebo-controlled pilot clinical trial on the efficacy of ayurvedic treatment regime on COVID-19 positive patients. Phytomedicine. 2021; $84: 153494$.

https://doi.org/10.1016/i.phymed.2021.153494 PMID:33596494

29. Dubée V, Roy PM, Vielle B, Parot-Schinkel E, Blanchet O, Darsonval A, Lefeuvre C, Abbara C, Boucher S, Devaud E, Robineau O, Rispal P, Guimard T, et al, and HYCOVID study group, and HYCOVID investigators, and Angers University Hospital, and Cholet Hospital, and Laval Hospital, and Le Mans Hospital, and Tours University Hospital, and Quimper Hospital, and La Roche sur Yon Hospital, and Tourcoing Hospital, and Orléans Hospital, and Nantes University Hospital, and Niort Hospital, and Lorient Hospital, and Brest University Hospital, and Cherbourg Hospital, and Saint-Brieuc Hospital, and Créteil - APHP University Hospital, and Saint-Antoine - APHP University Hospital, and Saint-Etienne University Hospital, and Toulouse University Hospital, and Melun Hospital, and Dijon University Hospital, and Princesse Grace Monaco Hospital, and Versailles Hospital, and Colmar Hospital, and Agen-Nerac Hospital, and Caen University Hospital, and Saint-Nazaire Hospital, and Nantes - Confluent Hospital, and Limoges University Hospital, and Poitiers University Hospital, and Amiens University Hospital, and Bobigny - APHP University Hospital, and Cergy-Pontoise Hospital, and Valencienne Hospital, and Valencienne - Clinique Tessier Hospital, and Henri-Mondor - APHP University Hospital, and Chalon-sur-Saône Hospital, and Marseille European Hospital, and Auxerre
Hospital, and Diaconnesses Croix-Saint-Simon Hospital, and Marseille - Saint Joseph Hospital, and Composition of the HYCOVID management team, and Steering committee, and Independant data safety and monitoring board, and Independent adjudication of clinical events committee, and Study management Coordination, and Data management. Hydroxychloroquine in mild-to-moderate coronavirus disease 2019: a placebo-controlled double blind trial. Clin Microbiol Infect. 2021; 27:1124-30.

https://doi.org/10.1016/j.cmi.2021.03.005 PMID:33813110

30. Eom JS, Ison M, Streinu-Cercel A, Săndulescu $O$, Preotescu LL, Kim YS, Kim JY, Cheon SH, Jang YR, Lee SJ, Kim SH, Chang I, Suh JH, et al. Efficacy and safety of CT-P59 plus standard of care: a phase $2 / 3$ randomized, double-blind, placebo-controlled trial in outpatients with mild-to-moderate SARS-CoV-2 infection. Research Square. 2021. https://doi.org/10.21203/rs.3.rs-296518/v1

31. Feld JJ, Kandel C, Biondi MJ, Kozak RA, Zahoor MA, Lemieux C, Borgia SM, Boggild AK, Powis J, McCready J, Tan DHS, Chan T, Coburn B, et al. Peginterferon lambda for the treatment of outpatients with COVID19: a phase 2, placebo-controlled randomised trial. Lancet Respir Med. 2021; 9:498-510.

https://doi.org/10.1016/S2213-2600(20)30566-X PMID:33556319

32. Gonzalez-Ochoa AJ, Raffetto JD, Hernández AG, Zavala N, Gutiérrez O, Vargas A, Loustaunau J. Sulodexide in the Treatment of Patients with Early Stages of COVID-19: A Randomized Controlled Trial. Thromb Haemost. 2021; 121:944-54. https://doi.org/10.1055/a-1414-5216 PMID:33677827

33. Gottlieb RL, Nirula A, Chen P, Boscia J, Heller B, Morris J, Huhn G, Cardona J, Mocherla B, Stosor V, Shawa I, Kumar P, Adams AC, et al. Effect of Bamlanivimab as Monotherapy or in Combination With Etesevimab on Viral Load in Patients With Mild to Moderate COVID-19: A Randomized Clinical Trial. JAMA. 2021; 325:632-44.

https://doi.org/10.1001/jama.2021.0202 PMID: 33475701

34. Gunst JD, Staerke NB, Pahus MH, Kristensen LH, Bodilsen J, Lohse N, Dalgaard LS, Brønnum D, Fröbert O, Hønge B, Johansen IS, Monrad I, Erikstrup C, et al. Efficacy of the TMPRSS2 inhibitor camostat mesilate in patients hospitalized with Covid-19-a double-blind randomized controlled trial. EClinicalMedicine. 2021; 35:100849.

https://doi.org/10.1016/i.eclinm.2021.100849 PMID:33903855 
35. Gupta A, Gonzalez-Rojas Y, Juarez E, Casal MC, Moya J, Falci DR, Sarkis E, Solis J, Zheng H, Scott N, Cathcart AL, Hebner CM, Sager J, et al. Early Covid-19 Treatment With SARS-CoV-2 Neutralizing Antibody Sotrovimab. medRxiv. 2021.

https://doi.org/10.1101/2021.05.27.21257096

36. Gutierrez-Castrellon P, Gandara-Marti T, Abreu AT, Nieto-Rufino CD, López-Orduña E, Jiménez-Escobar I, Jiménez-Gutiérrez C, López-Velazquez G, EspadalerMazo J. Efficacy and safety of novel probiotic formulation in adult Covid19 outpatients: a randomized, placebo-controlled clinical trial. medRxiv. 2021.

https://doi.org/10.1101/2021.05.20.21256954

37. Humeniuk R, Mathias A, Cao H, Osinusi A, Shen G, Chng E, Ling J, Vu A, German P. Safety, Tolerability, and Pharmacokinetics of Remdesivir, An Antiviral for Treatment of COVID-19, in Healthy Subjects. Clin Transl Sci. 2020; 13:896-906.

https://doi.org/10.1111/cts.12840 PMID: $\underline{32589775}$

38. Jagannathan $P$, Andrews JR, Bonilla $H$, Hedlin $H$, Jacobson KB, Balasubramanian $V$, Purington $N$, Kamble S, de Vries CR, Quintero O, Feng K, Ley C, Winslow $D$, et al. Peginterferon Lambda-1a for treatment of outpatients with uncomplicated COVID19: a randomized placebo-controlled trial. Nat Commun. 2021; 12:1967.

https://doi.org/10.1038/s41467-021-22177-1 PMID:33785743

39. Jeronimo CMP, Farias MEL, Val FFA, Sampaio VS, Alexandre MAA, Melo GC, Safe IP, Borba MGS, Netto RLA, Maciel ABS, Neto JRS, Oliveira LB, Figueiredo EFG, et al, and Metcovid Team. Methylprednisolone as Adjunctive Therapy for Patients Hospitalized With Coronavirus Disease 2019 (COVID-19; Metcovid): A Randomized, Double-blind, Phase IIb, Placebocontrolled Trial. Clin Infect Dis. 2021; 72:e373-81.

https://doi.org/10.1093/cid/ciaa1177 PMID: $\underline{32785710}$

40. Lenze EJ, Mattar C, Zorumski CF, Stevens A, Schweiger J, Nicol GE, Miller JP, Yang L, Yingling M, Avidan MS, Reiersen AM. Fluvoxamine vs Placebo and Clinical Deterioration in Outpatients With Symptomatic COVID-19: A Randomized Clinical Trial. JAMA. 2020; 324:2292-300.

https://doi.org/10.1001/jama.2020.22760 PMID: 33180097

41. López-Medina E, López $\mathrm{P}$, Hurtado IC, Dávalos DM, Ramirez O, Martínez E, Díazgranados JA, Oñate JM, Chavarriaga H, Herrera S, Parra B, Libreros G, Jaramillo $R$, et al. Effect of Ivermectin on Time to Resolution of Symptoms Among Adults With Mild COVID-19: A Randomized Clinical Trial. JAMA. 2021; 325:1426-35. https://doi.org/10.1001/jama.2021.3071 PMID:33662102

42. Marconi VC, Ramanan AV, de Bono S, Kartman CE, Krishnan V, Liao R, Goldman JD, Alatorre-Alexander J, Pellegrini RC, Estrada V, Som M, Cardoso A, Chakladar $S$, et al. Efficacy and safety of baricitinib in patients with COVID-19 infection: Results from the randomised, double-blind, placebo-controlled, parallel-group COV-BARRIER phase 3 trial. medRxiv. 2021.

https://doi.org/10.1101/2021.04.30.21255934

43. McCoy J, Goren A, Cadegiani FA, Vaño-Galván S, Kovacevic M, Situm M, Shapiro J, Sinclair R, Tosti A, Stanimirovic A, Fonseca D, Dorner E, Onety DC, et al. Proxalutamide Reduces the Rate of Hospitalization for COVID-19 Male Outpatients: A Randomized Double-Blinded Placebo-Controlled Trial. Front Med (Lausanne). 2021; 8:668698.

https://doi.org/10.3389/fmed.2021.668698 PMID:34350193

44. Mohan A, Tiwari P, Suri T, Mittal S, Patel A, Jain A, Velpandian T, Das UK, Bopanna TK, Pandey RM, Shelke $S$, Singh AR, Bhatnagar $S$, et al. Ivermectin in mild and moderate COVID-19 (RIVET-COV): a randomized, placebo-controlled trial. Research Square. 2021. https://doi.org/10.21203/rs.3.rs-191648/v1

45. Monk PD, Marsden RJ, Tear VJ, Brookes J, Batten TN, Mankowski M, Gabbay FJ, Davies DE, Holgate ST, Ho LP, Clark T, Djukanovic R, Wilkinson TMA, and Inhaled Interferon Beta COVID-19 Study Group. Safety and efficacy of inhaled nebulised interferon beta-1a (SNG001) for treatment of SARS-CoV-2 infection: a randomised, double-blind, placebo-controlled, phase 2 trial. Lancet Respir Med. 2021; 9:196-206.

https://doi.org/10.1016/S2213-2600(20)30511-7 PMID:33189161

46. Omrani AS, Pathan SA, Thomas SA, Harris TRE, Coyle PV, Thomas CE, Qureshi I, Bhutta ZA, Mawlawi NA, Kahlout RA, Elmalik A, Azad AM, Daghfal J, et al. Randomized double-blinded placebo-controlled trial of hydroxychloroquine with or without azithromycin for virologic cure of non-severe Covid-19. EClinicalMedicine. 2020; 29:100645. https://doi.org/10.1016/j.eclinm.2020.100645 PMID:33251500

47. Patel O, Chinni V, El-Khoury J, Perera M, Neto AS, McDonald C, See E, Jones D, Bolton D, Bellomo R, Trubiano J, Ischia J. A pilot double-blind safety and feasibility randomized controlled trial of high-dose intravenous zinc in hospitalized COVID-19 patients. J Med Virol. 2021; 93:3261-67. https://doi.org/10.1002/imv.26895 PMID: 
48. Puskarich MA, Cummins NW, Ingraham NE, Wacker DA, Reilkoff RA, Driver BE, Biros $M H$, Bellolio $F$, Chipman JG, Nelson AC, Beckman K, Langlois R, Bold $\mathrm{T}$, et al. A multi-center phase II randomized clinical trial of losartan on symptomatic outpatients with COVID-19. EClinicalMedicine. 2021; 37:100957.

https://doi.org/10.1016/i.eclinm.2021.100957

PMID:34195577

49. Rastogi A, Bhansali A, Khare N, Suri V, Yaddanapudi N, Sachdeva N, Puri GD, Malhotra P. Short term, highdose vitamin $D$ supplementation for COVID-19 disease: a randomised, placebo-controlled, study (SHADE study). Postgrad Med J. 2020. [Epub ahead of print].

https://doi.org/10.1136/postgradmedj-2020-139065 PMID: $\underline{33184146}$

50. Ravikirti, Roy R, Pattadar C, Raj R, Agarwal N, Biswas B, Manjhi PK, Rai DK, Shyama, Kumar A, Sarfaraz A. Evaluation of Ivermectin as a Potential Treatment for Mild to Moderate COVID-19: A Double-Blind Randomized Placebo Controlled Trial in Eastern India. J Pharm Pharm Sci. 2021; 24:343-50.

https://doi.org/10.18433/ipps32105

PMID:34265236

51. Reis G, Moreira Silva EADS, Medeiros Silva DC, Thabane L, Singh G, Park JJH, Forrest JI, Harari O, Quirino Dos Santos CV, Guimarães de Almeida APF, Figueiredo Neto AD, Savassi LCM, Milagres AC, et al, and TOGETHER Investigators. Effect of Early Treatment With Hydroxychloroquine or Lopinavir and Ritonavir on Risk of Hospitalization Among Patients With COVID-19: The TOGETHER Randomized Clinical Trial. JAMA Netw Open. 2021; 4:e216468.

https://doi.org/10.1001/jamanetworkopen.2021.6468 PMID:33885775

52. Rocco PRM, Silva PL, Cruz FF, Melo-Junior MAC, Tierno PFGMM, Moura MA, De Oliveira LFG, Lima CC, Dos Santos EA, Junior WF, Fernandes APSM, Franchini $K G$, Magri E, et al, and SARITA-2 investigators. Early use of nitazoxanide in mild COVID-19 disease: randomised, placebo-controlled trial. Eur Respir J. 2021; 58:2003725.

https://doi.org/10.1183/13993003.03725-2020

PMID:33361100

53. Salama C, Han J, Yau L, Reiss WG, Kramer B, Neidhart JD, Criner GJ, Kaplan-Lewis E, Baden R, Pandit L, Cameron ML, Garcia-Diaz J, Chávez V, et al. Tocilizumab in Patients Hospitalized with Covid-19 Pneumonia. N Engl J Med. 2021; 384:20-30.

https://doi.org/10.1056/NEJMoa2030340

PMID:33332779

54. Silva $M$, Espejo A, Pereyra ML, Lynch $M$, Thompson $\mathrm{M}$, Taconelli H, Baré P, Pereson MJ, Garbini M, Crucci
$P$, Enriquez D. Efficacy of Nitazoxanide in reducing the viral load in COVID-19 patients. Randomized, placebocontrolled, single-blinded, parallel group, pilot study. medRxiv. 2021.

https://doi.org/10.1101/2021.03.03.21252509

55. Sivapalan P, Suppli Ulrik C, Sophie Lapperre T, Dahlin Bojesen R, Eklöf J, Browatzki A, Torgny Wilcke J, Gottlieb V, Julius Håkansson KE, Tidemandsen C, Tupper O, Meteran H, Bergsøe C, et al, and ProPACCOVID study group. Azithromycin and hydroxychloroquine in hospitalised patients with confirmed COVID-19-a randomised double-blinded placebo-controlled trial. Eur Respir J. 2021; 2100752. [Epub ahead of print].

https://doi.org/10.1183/13993003.00752-2021 PMID:34083403

56. Skipper CP, Pastick KA, Engen NW, Bangdiwala AS, Abassi M, Lofgren SM, Williams DA, Okafor EC, Pullen MF, Nicol MR, Nascene AA, Hullsiek KH, Cheng MP, et al. Hydroxychloroquine in Nonhospitalized Adults With Early COVID-19 : A Randomized Trial. Ann Intern Med. 2020; 173:623-31.

https://doi.org/10.7326/M20-4207 PMID: $\underline{32673060}$

57. Stone JH, Frigault MJ, Serling-Boyd NJ, Fernandes AD, Harvey L, Foulkes AS, Horick NK, Healy BC, Shah R, Bensaci AM, Woolley AE, Nikiforow S, Lin N, et al, and BACC Bay Tocilizumab Trial Investigators. Efficacy of Tocilizumab in Patients Hospitalized with Covid-19. N Engl J Med. 2020; 383:2333-44.

https://doi.org/10.1056/NEJMoa2028836 PMID:33085857

58. Tardif JC, Bouabdallaoui N, L'Allier PL, Gaudet D, Shah $\mathrm{B}$, Pillinger $\mathrm{MH}$, Lopez-Sendon J, da Luz $\mathrm{P}$, Verret $\mathrm{L}$, Audet S, Dupuis J, Denault A, Pelletier M, et al, and COLCORONA Investigators. Colchicine for communitytreated patients with COVID-19 (COLCORONA): a phase 3, randomised, double-blinded, adaptive, placebo-controlled, multicentre trial. Lancet Respir Med. 2021; 9:924-32.

https://doi.org/10.1016/S2213-2600(21)00222-8 PMID:34051877

59. Tornling G, Batta R, Porter J, Bengtsson T, Parmar K, Kashiva R, Hallberg A, Cohrt AK, Westergaard K, Dalsgaard CJ, Raud J. The angiotensin type 2 receptor agonist C21 restores respiratory function in COVID19a double-blind, randomized, placebo-controlled Phase 2 trial. medRxiv. 2021.

https://doi.org/10.1101/2021.01.26.21250511

60. Ulrich RJ, Troxel AB, Carmody E, Eapen J, Bäcker M, DeHovitz JA, Prasad PJ, Li Y, Delgado C, Jrada M, Robbins GA, Henderson B, Hrycko A, et al. Treating COVID-19 With Hydroxychloroquine (TEACH): A 
Multicenter, Double-Blind Randomized Controlled Trial in Hospitalized Patients. Open Forum Infect Dis. 2020; 7:ofaa446.

https://doi.org/10.1093/ofid/ofaa446

PMID:33134417

61. Vallejos J, Zoni $R$, Bangher $M$, Villamandos $S$, Bobadilla A, Plano F, Campias C, Chaparro Campias E, Achinelli F, Guglielmone HA, Ojeda J, Medina F, Farizano Salazar D, et al. Ivermectin to prevent hospitalizations in patients with COVID-19 (IVERCORCOVID19): a structured summary of a study protocol for a randomized controlled trial. Trials. 2020; 21:965. https://doi.org/10.1186/s13063-020-04813-1 PMID:33234158

62. Wang $Y$, Zhang $D$, Du G, Du R, Zhao J, Jin $Y$, Fu S, Gao $L$, Cheng Z, Lu Q, Hu Y, Luo G, Wang K, et al. Remdesivir in adults with severe COVID-19: a randomised, double-blind, placebo-controlled, multicentre trial. Lancet. 2020; 395:1569-78.

https://doi.org/10.1016/S0140-6736(20)31022-9 PMID:32423584

63. Weinreich DM, Sivapalasingam S, Norton T, Ali S, Gao $H$, Bhore R, Musser BJ, Soo Y, Rofail D, Im J, Perry C, Pan C, Hosain R, et al, and Trial Investigators. REGNCOV2, a Neutralizing Antibody Cocktail, in Outpatients with Covid-19. N Engl J Med. 2021; 384:238-51.

https://doi.org/10.1056/NEJMoa2035002 PMID:33332778

64. Cao Y, Wei J, Zou L, Jiang T, Wang G, Chen L, Huang L, Meng F, Huang L, Wang N, Zhou X, Luo H, Mao Z, et al. Ruxolitinib in treatment of severe coronavirus disease 2019 (COVID-19): A multicenter, single-blind, randomized controlled trial. J Allergy Clin Immunol. 2020; 146:137-46.e3.

https://doi.org/10.1016/i.jaci.2020.05.019 PMID: $\underline{32470486}$

65. Cremer PC, Abbate A, Hudock K, McWilliams C, Mehta J, Chang SY, Sheng CC, Van Tassell B, Bonaventura A, Vecchié A, Carey B, Wang Q, Wolski $\mathrm{KE}$, et al, and MASH-COVID study group. Mavrilimumab in patients with severe COVID-19 pneumonia and systemic hyperinflammation (MASHCOVID): an investigator initiated, multicentre, doubleblind, randomised, placebo-controlled trial. Lancet Rheumatol. 2021; 3:e410-18.

https://doi.org/10.1016/S2665-9913(21)00070-9 PMID:33754144

66. de Alencar JCG, Moreira CL, Müller AD, Chaves CE, Fukuhara MA, da Silva EA, Miyamoto MFS, Pinto VB, Bueno CG, Lazar Neto F, Gomez Gomez LM, Menezes MCS, Marchini JFM, et al, and COVID Register Group. Double-blind, Randomized, Placebo-controlled Trial
With N-acetylcysteine for Treatment of Severe Acute Respiratory Syndrome Caused by Coronavirus Disease 2019 (COVID-19). Clin Infect Dis. 2021; 72:e736-41.

https://doi.org/10.1093/cid/ciaa1443

PMID:32964918

67. Dequin PF, Heming N, Meziani F, Plantefève G, Voiriot G, Badié J, François B, Aubron C, Ricard JD, Ehrmann $S$, Jouan $Y$, Guillon A, Leclerc $M$, et al, and CAPE COVID Trial Group and the CRICS-TrigGERSep Network. Effect of Hydrocortisone on 21-Day Mortality or Respiratory Support Among Critically III Patients With COVID-19: A Randomized Clinical Trial. JAMA. 2020; 324:1298-306.

https://doi.org/10.1001/jama.2020.16761

PMID: $\underline{2876689}$

68. Gharebaghi N, Nejadrahim R, Mousavi SJ, SadatEbrahimi SR, Hajizadeh R. The use of intravenous immunoglobulin gamma for the treatment of severe coronavirus disease 2019: a randomized placebocontrolled double-blind clinical trial. BMC Infect Dis. 2020; 20:786.

https://doi.org/10.1186/s12879-020-05507-4 PMID:33087047

69. Lescure FX, Honda H, Fowler RA, Lazar JS, Shi G, Wung P, Patel N, Hagino O, and Sarilumab COVID-19 Global Study Group. Sarilumab in patients admitted to hospital with severe or critical COVID-19: a randomised, double-blind, placebo-controlled, phase 3 trial. Lancet Respir Med. 2021; 9:522-32. https://doi.org/10.1016/S2213-2600(21)00099-0 PMID: 33676590

70. Libster R, Pérez Marc G, Wappner D, Coviello S, Bianchi A, Braem V, Esteban I, Caballero MT, Wood C, Berrueta M, Rondan A, Lescano G, Cruz P, et al, and Fundación INFANT-COVID-19 Group. Early High-Titer Plasma Therapy to Prevent Severe Covid-19 in Older Adults. N Engl J Med. 2021; 384:610-18.

https://doi.org/10.1056/NEJMoa2033700 PMID:33406353

71. Munch MW, Meyhoff TS, Helleberg M, Kjaer MN, Granholm A, Hjorts $\varnothing$ CJS, Jensen TS, Møller MH, Hjortrup PB, Wetterslev M, Vesterlund GK, Russell L, Jørgensen $V L$, et al. Low-dose hydrocortisone in patients with COVID-19 and severe hypoxia: the COVID STEROID randomised, placebo-controlled trial. Acta Anaesthesiol Scand. 2021. [Epub ahead of print]. https://doi.org/10.1111/aas.13941 PMID:34138478

72. Rosas IO, Bräu N, Waters $M$, Go RC, Hunter BD, Bhagani S, Skiest D, Aziz MS, Cooper N, Douglas IS, Savic S, Youngstein T, Del Sorbo L, et al. Tocilizumab in Hospitalized Patients with Severe Covid-19 Pneumonia. N Engl J Med. 2021; 384:1503-16. 
https://doi.org/10.1056/NEJMoa2028700 PMID:33631066

73. Sehgal IS, Guleria R, Singh S, Siddiqui MS, Agarwal R. A randomised trial of Mycobacterium $w$ in critically ill patients with COVID-19: ARMY-1. ERJ Open Res. 2021; 7:00059-2021.

https://doi.org/10.1183/23120541.00059-2021 PMID:34031642

74. Shi L, Huang $H$, Lu $X$, Yan $X$, Jiang $X, X u R$, Wang $S$, Zhang C, Yuan X, Xu Z, Huang L, Fu JL, Li Y, et al. Effect of human umbilical cord-derived mesenchymal stem cells on lung damage in severe COVID-19 patients: a randomized, double-blind, placebo-controlled phase 2 trial. Signal Transduct Target Ther. 2021; 6:58. https://doi.org/10.1038/s41392-021-00488-5 PMID: $\underline{3568628}$

75. Simonovich VA, Burgos Pratx LD, Scibona $P$, Beruto MV, Vallone MG, Vázquez C, Savoy N, Giunta DH, Pérez LG, Sánchez MDL, Gamarnik AV, Ojeda DS, Santoro DM, et al, and PlasmAr Study Group. A Randomized Trial of Convalescent Plasma in Covid-19 Severe Pneumonia. N Engl J Med. 2021; 384:619-29. https://doi.org/10.1056/NEJMoa2031304 PMID:33232588

76. Sivapalasingam $S$, Lederer $D$, Bhore $R$, Hajizadeh $N$, Criner G, Hossain R, Mahmood A, Giannelou A, Somersan-Karakaya S, O’Brien M, Boyapati A, Parrino J, Musser B, et al. A Randomized Placebo-Controlled Trial of Sarilumab in Hospitalized Patients with Covid19. medRxiv. 2021. https://doi.org/10.1101/2021.05.13.21256973

77. Temesgen Z, Burger CD, Baker J, Polk C, Libertin C, Kelley C, Marconi VC, Orenstein R, Durrant C, Chappell D, Ahmed O, Chappell G, Badley AD. Lenzilumab efficacy and safety in newly hospitalized covid-19 subjects: results from the live-air phase 3 randomized double-blind placebo-controlled trial. medRxiv. 2021:2021.05.01.21256470.

https://doi.org/10.1101/2021.05.01.21256470 PMID:33972949

78. Zhong $M$, Sun $A$, Xiao $T$, Yao G, Sang L, Zheng $X$, Zhang J, Jin X, Xu L, Yang W, Wang P, Hu K, Zhang D, et al. A Randomized, Single-blind, Group sequential, Activecontrolled Study to evaluate the clinical efficacy and safety of $\alpha$-Lipoic acid for critically ill patients with coronavirus disease 2019 (COVID-19). medRxiv. 2020. https://doi.org/10.1101/2020.04.15.20066266

79. Siemieniuk RA, Bartoszko JJ, Ge L, Zeraatkar D, Izcovich A, Kum E, Pardo-Hernandez H, Qasim A, Martinez JPD, Rochwerg B, Lamontagne F, Han MA, Liu $Q$, et al. Drug treatments for covid-19: living systematic review and network meta-analysis. BMJ. 2020; 370:m2980. https://doi.org/10.1136/bmj.m2980

PMID: $\underline{32732190}$

80. Mauvais-Jarvis F. Do Anti-androgens Have Potential as Therapeutics for COVID-19? Endocrinology. 2021; 162:bqab114.

https://doi.org/10.1210/endocr/bqab114

PMID:34089595

81. Ramos I, Fernandez-Sesma A. Modulating the Innate Immune Response to Influenza A Virus: Potential Therapeutic Use of Anti-Inflammatory Drugs. Front Immunol. 2015; 6:361.

https://doi.org/10.3389/fimmu.2015.00361

PMID:26257731

82. Hosseini A, Dolati S, Hashemi V, AbdollahpourAlitappeh M, Yousefi M. Regulatory T and T helper 17 cells: Their roles in preeclampsia. J Cell Physiol. 2018; 233:6561-73.

https://doi.org/10.1002/jcp.26604

PMID:29663372

83. Richards $\mathrm{MH}$, Getts MT, Podojil JR, Jin YH, Kim BS, Miller SD. Virus expanded regulatory $T$ cells control disease severity in the Theiler's virus mouse model of MS. J Autoimmun. 2011; 36:142-54.

https://doi.org/10.1016/j.jaut.2010.12.005

PMID:21273044

84. Qiao Y, Kolibaba H, Mori Y, Liu T, Chen H, Guo J, Xu D, Zhang Y. Infection of Placental Extravillous Cytotrophoblasts with Human Cytomegalovirus Causes a Treg/Th17 Imbalance at the Maternal-Fetal Interface. Cell Transplant. 2020; 29:963689720925055.

https://doi.org/10.1177/0963689720925055 PMID:32693638

85. Kaur H, Shekhar N, Sharma S, Sarma P, Prakash A, Medhi B. Ivermectin as a potential drug for treatment of COVID-19: an in-sync review with clinical and computational attributes. Pharmacol Rep. 2021; 73:736-49.

https://doi.org/10.1007/s43440-020-00195-y PMID: $\underline{3389725}$

86. Vita S, Centanni D, Lanini S, Piselli P, Rosati S, Giancola ML, Mondi A, Pinnetti C, Topino S, Chinello P, Mosti S, Gualano G, Faraglia F, et al, and On Behalf Of The ReCOVeRI Study Group. Benefits of Steroid Therapy in COVID-19 Patients with Different $\mathrm{PaO}_{2} / \mathrm{FiO}_{2}$ Ratio at Admission. J Clin Med. 2021; 10:3236.

https://doi.org/10.3390/jcm10153236 PMID:34362021

87. Miller J, Bruen C, Schnaus M, Zhang J, Ali S, Lind A, Stoecker Z, Stauderman K, Hebbar S. Auxora versus standard of care for the treatment of severe or critical COVID-19 pneumonia: results from a randomized controlled trial. Crit Care. 2020; 24:502. 
https://doi.org/10.1186/s13054-020-03220-x

PMID:32795330

88. Rajendran K, Krishnasamy N, Rangarajan J, Rathinam J, Natarajan M, Ramachandran A. Convalescent plasma transfusion for the treatment of COVID-19: Systematic review. J Med Virol. 2020; 92:1475-83. https://doi.org/10.1002/imv.25961 PMID:32356910

89. Tleyjeh IM, Kashour Z, Damlaj M, Riaz M, Tlayjeh H, Altannir M, Altannir Y, Al-Tannir M, Tleyjeh R, Hassett L, Kashour T. Efficacy and safety of tocilizumab in COVID-19 patients: a living systematic review and meta-analysis. Clin Microbiol Infect. 2021; 27:215-27. https://doi.org/10.1016/i.cmi.2020.10.036

PMID:33161150

90. La Rosée F, Bremer HC, Gehrke I, Kehr A, Hochhaus A, Birndt S, Fellhauer M, Henkes M, Kumle B, Russo SG, La Rosée $P$. The Janus kinase $1 / 2$ inhibitor ruxolitinib in COVID-19 with severe systemic hyperinflammation. Leukemia. 2020; 34:1805-15.

https://doi.org/10.1038/s41375-020-0891-0

PMID:32518419 


\section{SUPPLEMENTARY MATERIALS}

\section{Supplementary Figures}
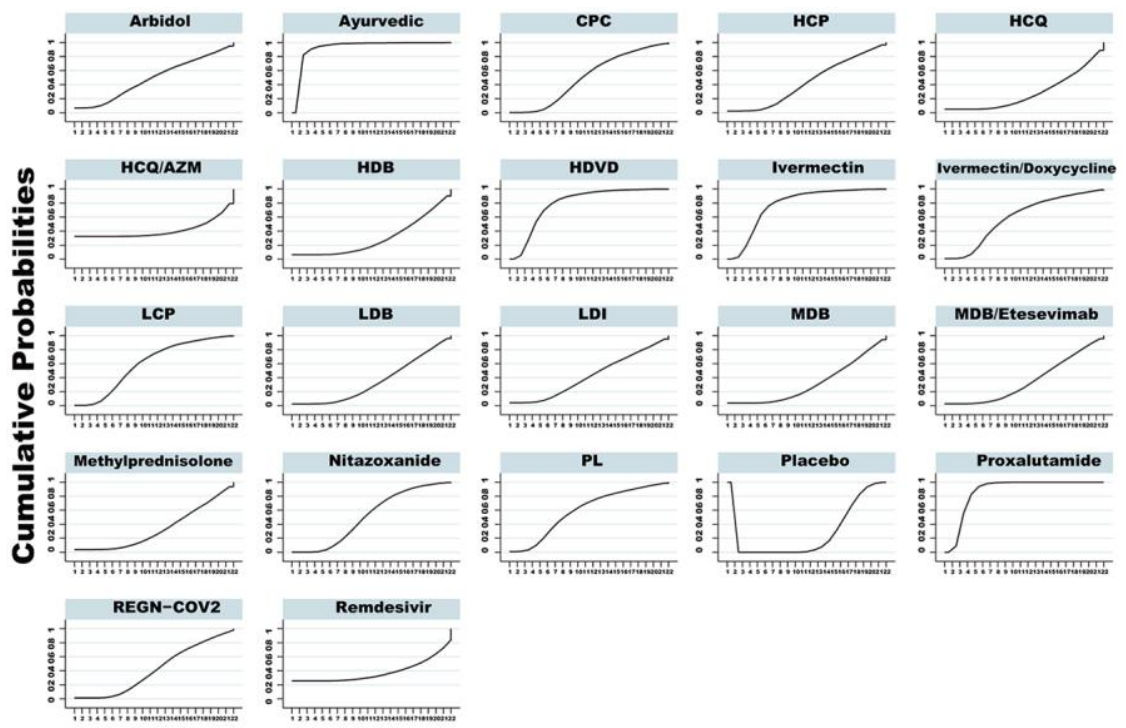

Graphs by Treatment

Rank

Treatment Relative Ranking of Model 1

\begin{tabular}{|c|c|c|c|}
\hline Treatment & SUCRA & PrBest & MeanRank \\
\hline Placebo & 31.1 & 0.0 & 15.5 \\
\hline Arbidol & 48.8 & 6.7 & 11.7 \\
\hline Ayurvedic & 92.9 & 0.0 & 2.5 \\
\hline CPC & 50.5 & 0.3 & 11.4 \\
\hline HCP & 43.3 & 2.4 & 12.9 \\
\hline HCQ & 28.4 & 4.8 & 16.0 \\
\hline $\mathrm{HCQ} / \mathrm{AZM}$ & 41.1 & 32.4 & 13.4 \\
\hline HDB & 30.1 & 6.5 & 15.7 \\
\hline HDVD & 79.8 & 0.0 & 5.3 \\
\hline Ivermectin & 77.6 & 0.1 & 5.7 \\
\hline Ivermectin/Doxycycline & 59.8 & 0.8 & 9.5 \\
\hline LCP & 60.0 & 0.5 & 9.4 \\
\hline LDB & 35.1 & 2.6 & 14.6 \\
\hline LDI & 42.7 & 4.3 & 13.0 \\
\hline MDB & 32.4 & 3.7 & 15.2 \\
\hline MDB/Etesevimab & 35.7 & 2.7 & 14.5 \\
\hline Methylprednisolone & 33.5 & 4.0 & 15.0 \\
\hline Nitazoxanide & 51.8 & 0.3 & 11.1 \\
\hline $\mathrm{PL}$ & 59.4 & 1.0 & 9.5 \\
\hline Proxalutamide & 87.5 & 0.0 & 3.6 \\
\hline REGN-COV2 & 44.0 & 1.3 & 12.8 \\
\hline Remdesivir & 39.3 & 25.5 & 13.7 \\
\hline
\end{tabular}

Supplementary Figure 1. Treatment ranking and SUCRA plot for the virological cure ratio among non-severe COVID-19 patients. "Larger SUCRAs denote more effective interventions. Abbreviations: SUCRA: surface under the cumulative ranking area; COVID-19: coronavirus disease 2019; PL: peginterferon lambda; LDI: low dosage ivermectin; AZM: azithromycin; HDVD: high-dose vitamin D; LCP: low dosage CT-P59; HCP: high dosage CT-P59; CPC: CT-P59 combined; HCQ: hydroxychloroquine; LDB: low dosage bamlanivimab; MDB: moderate dosage bamlanivimab; HDB: high dosage bamlanivimab. 

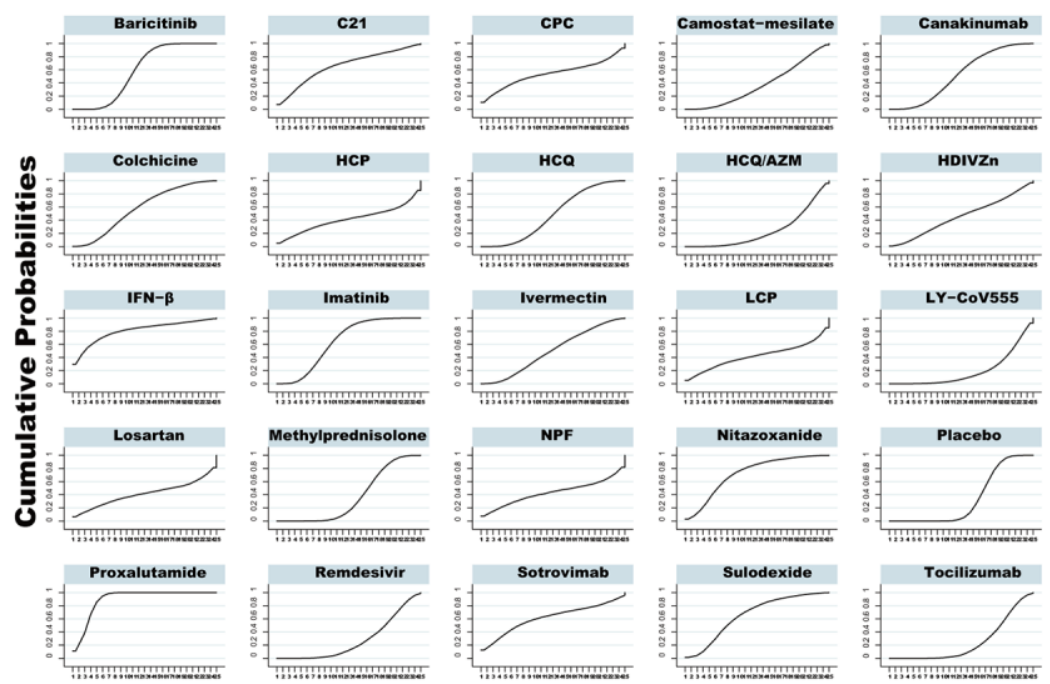

Graphs by Treatment

Rank

Treatment Relative Ranking of Model 1

\begin{tabular}{|r|r|r|r|}
\hline Treatment & SUCRA & PrBest & MeanRank \\
\hline Placebo & 33.9 & 0.0 & 16.9 \\
Baricitinib & 59.2 & 0.0 & 10.8 \\
C21 & 65.9 & 7.1 & 9.2 \\
CPC & 53.9 & 10.5 & 12.1 \\
Camostat-mesilate & 37.0 & 0.0 & 16.1 \\
Canakinumab & 52.4 & 0.0 & 12.4 \\
Colchicine & 58.0 & 0.1 & 11.1 \\
HCP & 41.4 & 4.9 & 15.1 \\
HCQ & 48.6 & 0.0 & 13.3 \\
HCQ/AZM & 24.0 & 0.0 & 19.2 \\
HDIVZn & 45.8 & 0.7 & 14.0 \\
IFN- $\beta$ & 80.6 & 29.7 & 5.6 \\
Imatinib & 64.7 & 0.0 & 9.5 \\
Ivermectin & 49.9 & 0.1 & 13.0 \\
LCP & 42.3 & 5.1 & 14.8 \\
LY-CoV555 & 19.6 & 0.0 & 20.3 \\
Losartan & 41.4 & 6.6 & 15.1 \\
NPF & 36.8 & 0.0 & 16.2 \\
Methylprednisolone & 43.3 & 7.5 & 14.6 \\
Nitazoxanide & 72.4 & 2.9 & 7.6 \\
Proxalutamide & 91.4 & 11.1 & 3.1 \\
Remdesivir & 29.7 & 0.0 & 17.9 \\
Sotrovimab & 63.0 & 12.5 & 9.9 \\
Sulodexide & 67.8 & 1.2 & 8.7 \\
Tocilizumab & 26.9 & 0.0 & 18.5 \\
\hline & & & \\
\hline
\end{tabular}

Supplementary Figure 2. Treatment ranking and SUCRA plot for all-cause mortality among non-severe COVID-19 patients. *Larger SUCRAs denote less all-cause mortality. Abbreviations: SUCRA: surface under the cumulative ranking area; COVID-19: coronavirus disease 2019; HCQ: hydroxychloroquine; AZM: azithromycin; HDIVZn: high-dose intravenous zinc; IFN- $\beta$ : interferon beta; NPF: novel probiotic formulation; LCP: low dosage CT-P59; HCP: high dosage CT-P59; CPC: CT-P59 combined. 


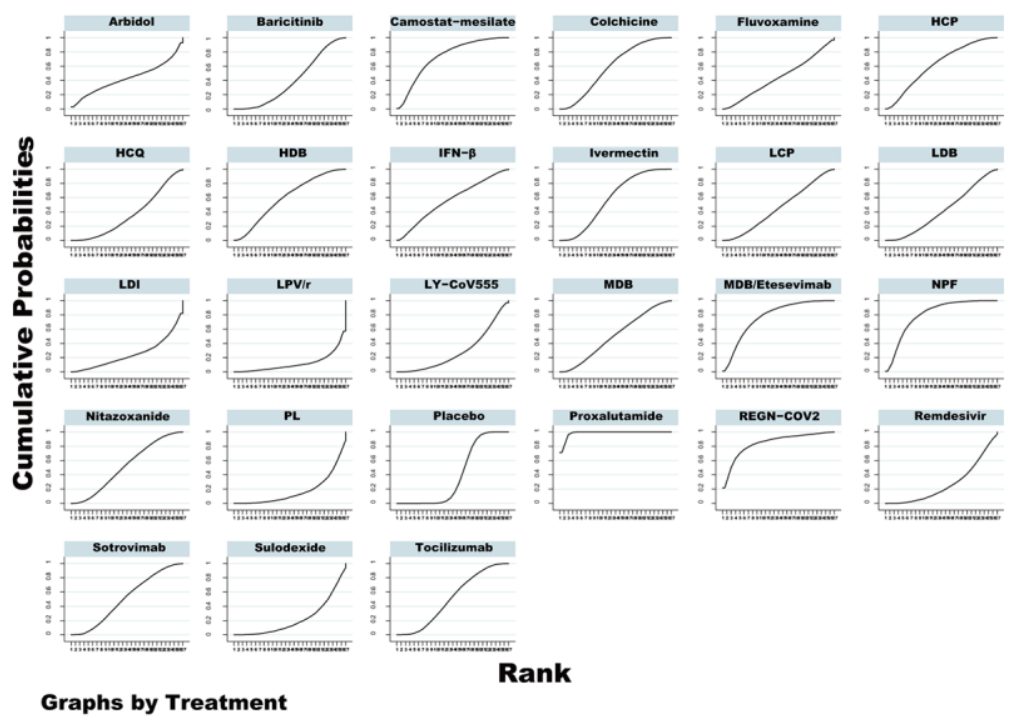

Treatment Relative Ranking of Model 1

\begin{tabular}{|c|c|c|c|}
\hline Treatment & SUCRA & PrBest & MeanRank \\
\hline Placebo & 39.5 & 0.0 & 16.7 \\
\hline Arbidol & 43.2 & 3.0 & 15.8 \\
\hline Baricitinib & 40.1 & 0.0 & 16.6 \\
\hline Camostat-mesilate & 73.2 & 0.7 & 8.0 \\
\hline Colchicine & 59.1 & 0.0 & 11.6 \\
\hline Fluvoxamine & 44.5 & 0.2 & 15.4 \\
\hline $\mathrm{HCP}$ & 62.3 & 0.3 & 10.8 \\
\hline $\mathrm{HCQ}$ & 36.6 & 0.0 & 17.5 \\
\hline $\mathrm{HDB}$ & 59.9 & 0.1 & 11.4 \\
\hline IFN- $\beta$ & 56.5 & 0.3 & 12.3 \\
\hline Ivermectin & 58.7 & 0.0 & 11.7 \\
\hline LCP & 45.9 & 0.0 & 15.1 \\
\hline LDB & 42.1 & 0.0 & 16.0 \\
\hline LDI & 25.0 & 0.1 & 20.5 \\
\hline $\mathrm{LPV} / \mathrm{r}$ & 11.9 & 0.0 & 23.9 \\
\hline LY-CoV555 & 29.2 & 0.0 & 19.4 \\
\hline MDB & 50.6 & 0.0 & 13.8 \\
\hline $\mathrm{MDB} /$ Etesevimab & 77.0 & 1.2 & 7.0 \\
\hline $\mathrm{NPF}$ & 80.3 & 0.9 & 6.1 \\
\hline Nitazoxanide & 52.2 & 0.0 & 13.4 \\
\hline $\mathrm{PL}$ & 18.8 & 0.0 & 22.1 \\
\hline Proxalutamide & 98.7 & 71.4 & 1.3 \\
\hline REGN-COV2 & 85.6 & 21.7 & 4.7 \\
\hline Remdesivir & 29.2 & 0.0 & 19.4 \\
\hline Sotrovimab & 53.1 & 0.0 & 13.2 \\
\hline Sulodexide & 23.8 & 0.0 & 20.8 \\
\hline Tocilizumab & 52.8 & 0.0 & 13.3 \\
\hline
\end{tabular}

Supplementary Figure 3. Treatment ranking and SUCRA plot for the ratio of treatment-emergent adverse events among non-severe COVID-19 patients. " Larger SUCRAs denote less treatment-emergent adverse events. Abbreviations: SUCRA: surface under the cumulative ranking area; COVID-19: coronavirus disease 2019; PL: peginterferon lambda; LDI: low dosage ivermectin; IFN- $\beta$ : interferon beta; NPF: novel probiotic formulation; LPV/r: lopinavir-ritonavir; LCP: low dosage CT-P59; HCP: high dosage CT-P59; LDB: low dosage bamlanivimab; MDB: moderate dosage bamlanivimab; HDB: high dosage bamlanivimab. 

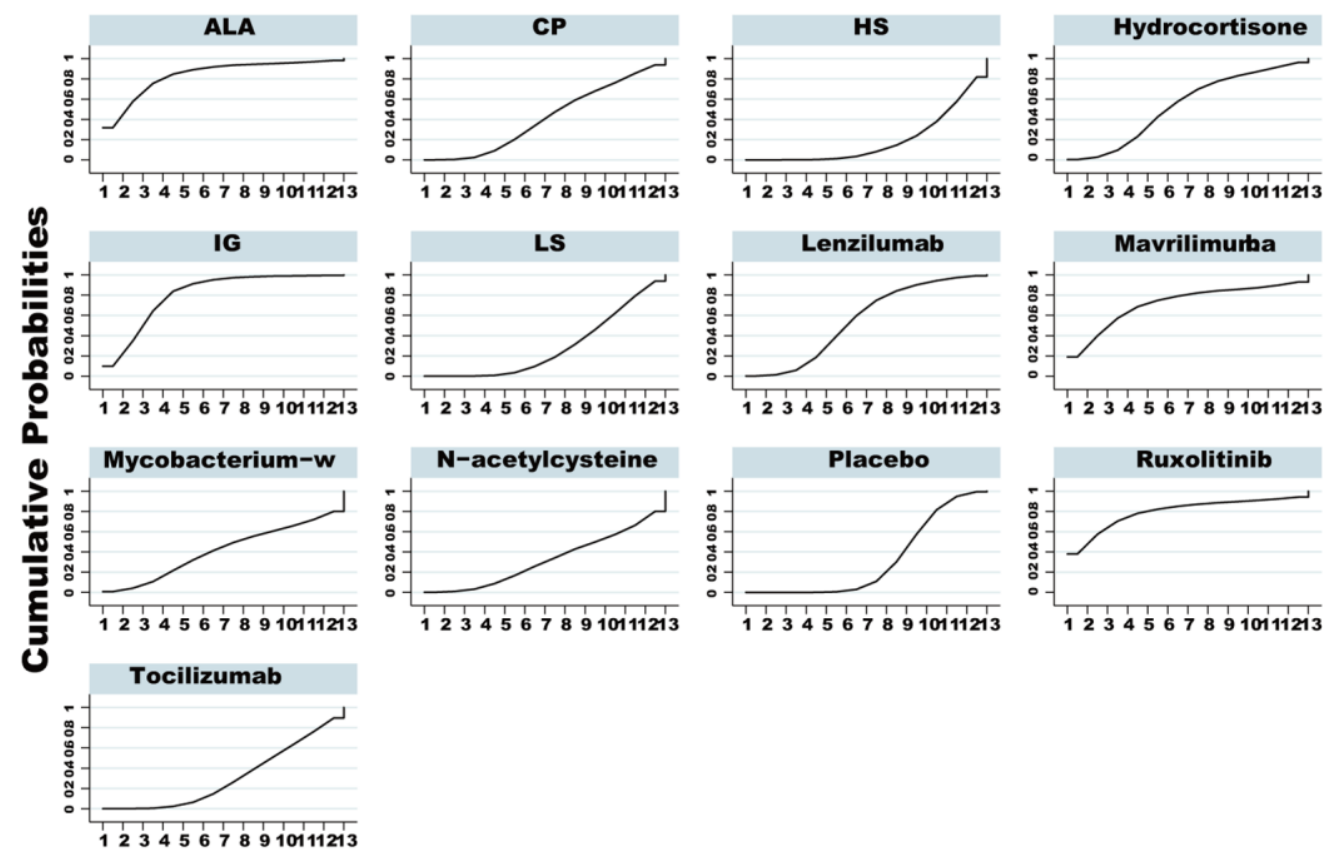

Graphs by Treatment

\section{Rank}

Treatment Relative Ranking of Model 1

\begin{tabular}{|r|r|r|r|}
\hline Treatment & SUCRA & PrBest & MeanRank \\
\hline Placebo & 31.3 & 0.0 & 9.2 \\
ALA & 83.0 & 29.2 & 3.0 \\
CP & 41.6 & 0.0 & 8.0 \\
HS & 19.1 & 0.0 & 10.7 \\
IG & 80.7 & 9.2 & 6.5 \\
LS & 28.6 & 0.0 & 3.3 \\
Hydrocortisone & 53.8 & 0.2 & 9.6 \\
Lenzilumab & 55.3 & 0.2 & 4.3 \\
Mavrilimumab & 72.6 & 19.6 & 8.1 \\
Mycobacterium-w & 40.8 & 0.8 & 9.1 \\
N-acetylcysteine & 32.4 & 0.1 & 3.4 \\
Ruxolitinib & 79.8 & 40.6 & 9.3 \\
Tocilizumab & 30.8 & 0.0 & \\
\hline
\end{tabular}

Supplementary Figure 4. Treatment ranking and SUCRA plot for all-cause mortality among severe COVID-19 patients. ${ }^{*}$ Larger SUCRAs denote less treatment-emergent adverse events. Abbreviations: SUCRA: surface under the cumulative ranking area; COVID-19: coronavirus disease 2019; LS: low dosage sarilumab; HS: high dosage sarilumab; CP: convalescent plasma; ALA: $\alpha$-Lipoic acid; IG: immunoglobulin gamma. 


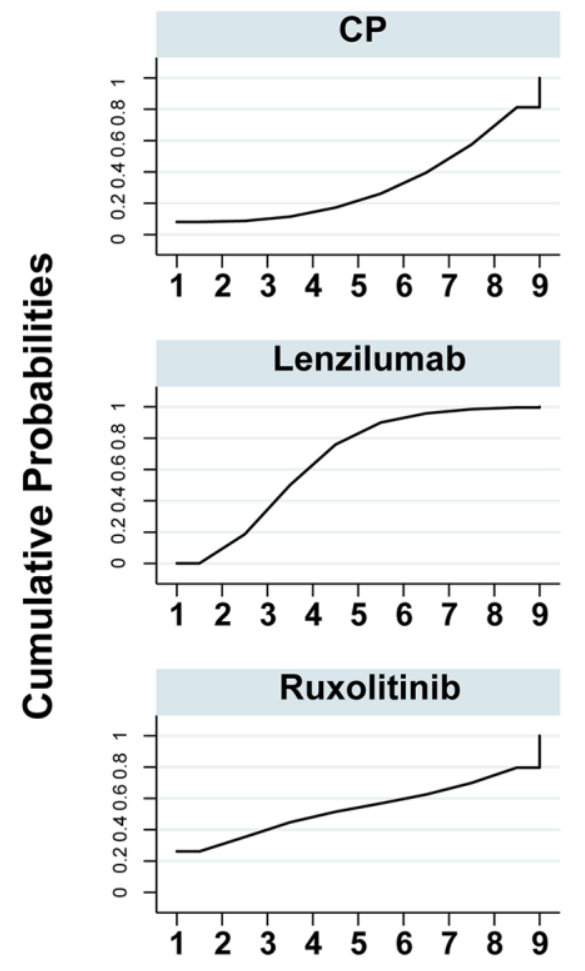

\section{Graphs by Treatment}

HS
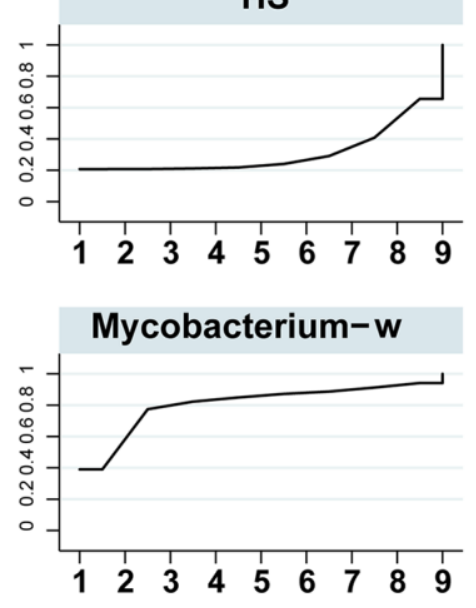

Tocilizumab

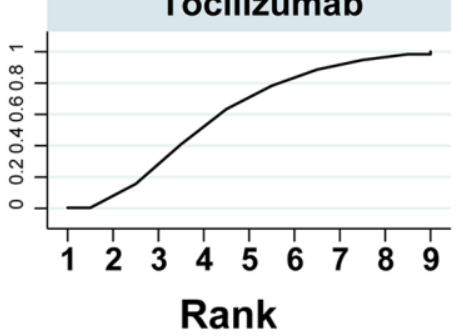

LS

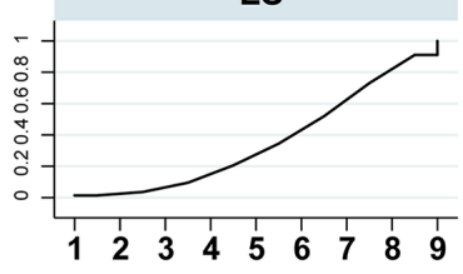

Placebo

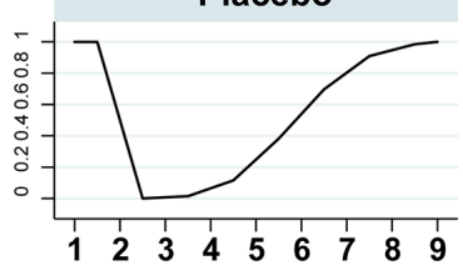

UC-MSCs

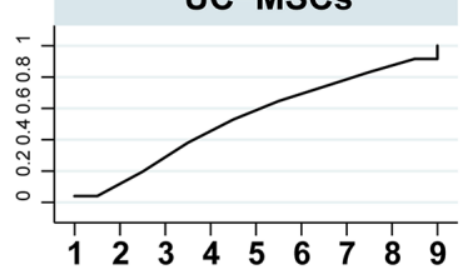

Treatment Relative Ranking of Model 1

\begin{tabular}{|r|r|r|r|}
\hline Treatment & SUCRA & PrBest & MeanRank \\
\hline Placebo & 51.3 & 0.1 & 4.9 \\
CP & 31.3 & 8.1 & 6.5 \\
HS & 30.5 & 20.7 & 6.6 \\
LS & 35.7 & 1.4 & 6.1 \\
Lenzilumab & 66.1 & 0.1 & 3.7 \\
Mycobacterium-w & 80.6 & 39.0 & 2.6 \\
Ruxolitinib & 53.3 & 26.2 & 4.7 \\
Tocilizumab & 60.1 & 0.4 & 4.2 \\
UC-MSCs & 53.5 & 4.0 & 4.7 \\
\hline
\end{tabular}

Supplementary Figure 5. Treatment ranking and SUCRA plot for the ratio of treatment-emergent adverse events among severe COVID-19 patients. Severe COVID-19 patients. "Larger SUCRAs denote less treatment-emergent adverse events. Abbreviations: SUCRA: surface under the cumulative ranking area; COVID-19: coronavirus disease 2019; LS: low dosage sarilumab; HS: high dosage sarilumab; CP: convalescent plasma. 

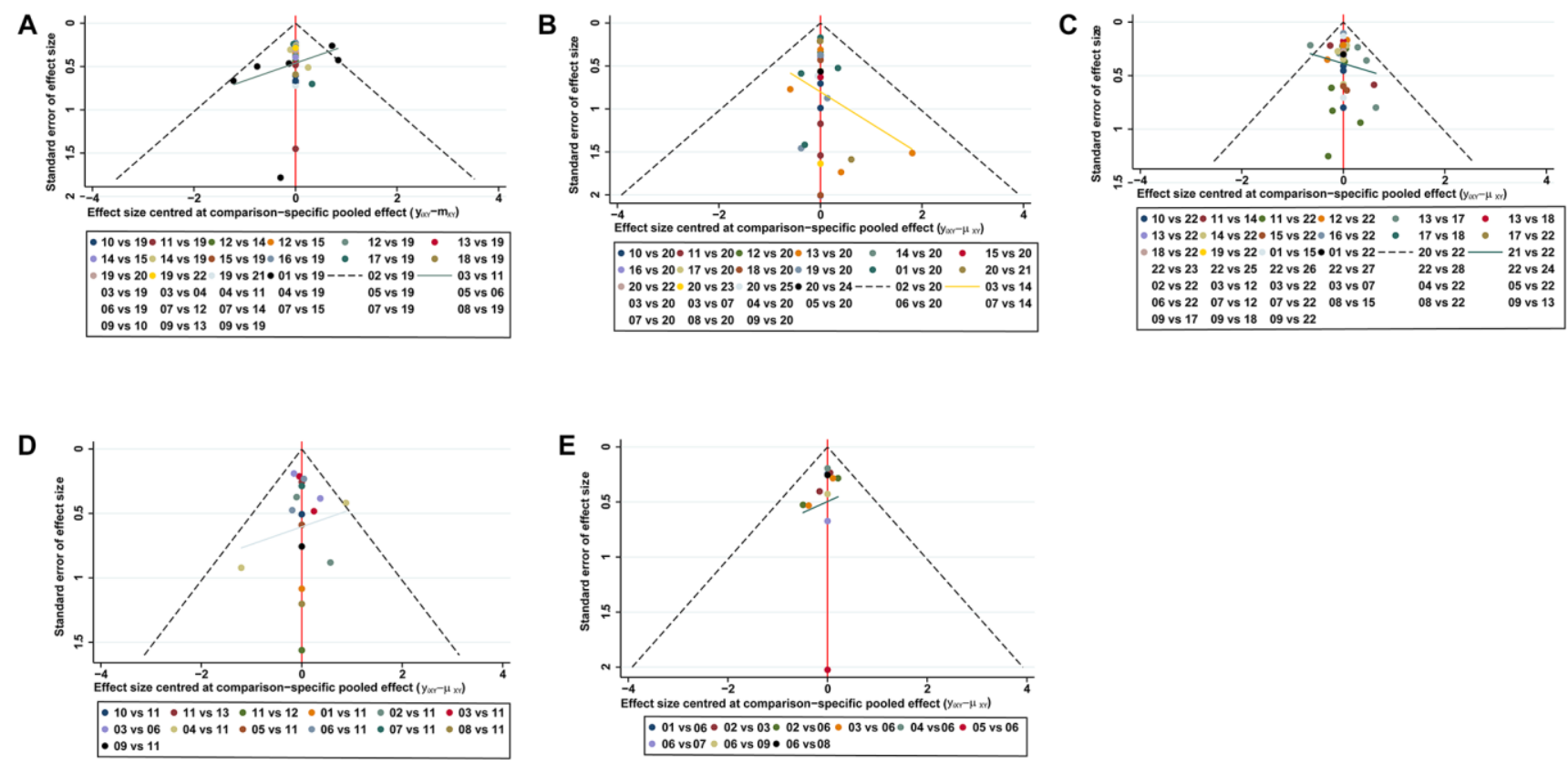

Supplementary Figure 6. Funnel plots of publication bias for the efficacy and safety of medications. (A) the ratio of virological cure for non-severe COVID-19 patients (01: arbidol; 02: ayurvedic; 03: CPC; 04: HCP; 05: HCQ; 06: HCQ/AZM; 07: HDB; 08: HDVD; 09: ivermectin; 10: ivermectin/doxycycline; 11: LCP; 12: LDB; 13: LDI; 14: MDB; 15: MDB/etesevimab; 16: methylprednisolone; 17: nitazoxanide; 18: PL; 19: placebo; 20: proxalutamide; 21: REGN-COV2; 22: remdesivir). (B) All-cause mortality for non-severe COVID-19 patients (01: baricitinib; 02: C21; 03: CPC; 04: camostat-mesilate; 05: canakinumab; 06: colchicine; 07: HCP; 08: HCQ; 09: HCQ/AZM; 10: HDIVZn; 11: IFN- $\beta$; 12: imatinib; 13: ivermectin; 14: LCP; 15: LY-CoV555; 16: losartan; 17: methylprednisolone; 18: NPF; 19: nitazoxanide; 20: placebo; 21: proxalutamide; 22: remdesivir; 23: sotrovimab; 24: sulodexide; 25: tocilizumab). (C) The ratio of treatment-emergent adverse events for nonsevere COVID-19 patients (01: arbidol; 02: baricitinib; 03: camostat-mesilate; 04: colchicine; 05: fluvoxamine; 06: HCP; 07: HCQ; 08: HDB; 09: IFN- $\beta$; 10: ivermectin; 11: LCP; 12: LDB;13: LDI; 14: LPV/r; 15: LY-CoV555; 16: MDB; 17: MDB/etesevimab; 18: NPF; 19: nitazoxanide; 20: PL; 21: placebo; 22: proxalutamide; 23: REGN-COV2; 24: remdesivir; 25: sotrovimab; 26: sulodexide; 27: tocilizumab). (D) All-cause mortality of severe COVID-19 patients (01: ALA; 02: CP; 03: HS; 04: hydrocortisone; 05: IG; 06: LS; 07: lenzilumab; 08: mavrilimumab; 09: mycobacteriumw; 10: N-acetylcysteine; 11: placebo; 12: ruxolitinib; 13: tocilizumab). (E). The TEAEs ratio of severe COVID-19 patients (01: CP; 02: HS; 03: LS; 04: lenzilumab; 05: mycobacterium-w; 06: placebo; 07: ruxolitinib; 08: tocilizumab; 09: UC-MSCs). Abbreviations: COVID-19: coronavirus disease 2019; VC: virological cure; TEAEs: treatment-emergent adverse events; PL: peginterferon lambda; LDI: low dosage ivermectin; LPV/r: lopinavir-ritonavir; AZM: azithromycin; HDVD: high-dose vitamin D; HDIVZn: high-dose intravenous zinc: LCP: low dosage CT-P59; HCP: high dosage CT-P59; CPC: CT-P59 combined; HCQ: hydroxychloroquine; LDB: low dosage bamlanivimab; MDB: moderate dosage bamlanivimab; HDB: high dosage bamlanivimab; LS: low dosage sarilumab; HS: high dosage sarilumab; NPF: novel probiotic formulation; CP: convalescent plasma; ALA: $\alpha$-Lipoic acid; IFN- $\beta$ : interferon beta; IG: immunoglobulin gamma. 


\section{Supplementary Tables}

Please browse Full Text version to see the data of Supplementary Tables 1-2 and Appendix Files 1-2.

Supplementary Table 1. Characteristics of randomized placebo-controlled trials of pharmacological interventions versus placebo in severe or non-severe patients with COVID-19.

Supplementary Table 2. Rating of individual items of the Risk of Bias tool for each study.

Supplementary Table 3. Risk of bias table of included studies.

\begin{tabular}{|c|c|c|c|}
\hline Study ID (reference) & $\begin{array}{c}\text { Low risk of bias } \\
(\%)\end{array}$ & $\begin{array}{c}\text { High risk of bias } \\
(\%)\end{array}$ & $\begin{array}{c}\text { Unclear risk of bias } \\
(\%)\end{array}$ \\
\hline ACTIV-3/TICO LY-CoV555 Study Group [18] & 85.71 & 0 & 14.29 \\
\hline Ahmed S et al. [19] & 71.43 & 0 & 28.57 \\
\hline Ahmed S et al. [19] & 71.43 & 0 & 28.57 \\
\hline Aman J et al. [20] & 71.43 & 0 & 28.57 \\
\hline Biber A et al. [21] & 71.43 & 0 & 28.57 \\
\hline Blum VF et al. [22] & 71.43 & 0 & 28.57 \\
\hline Cadegiani FA et al. (a) [23] & 85.71 & 0 & 14.29 \\
\hline Cadegiani FA et al. (b) [24] & 71.43 & 0 & 28.57 \\
\hline Caricchio R et al. [25] & 71.43 & 0 & 28.57 \\
\hline Chaccour C et al. [26] & 57.14 & 0 & 42.86 \\
\hline Chen J et al. [27] & 57.14 & 0 & 42.86 \\
\hline Devpura G et al. [28] & 71.43 & 0 & 28.57 \\
\hline Dubee V et al. [29] & 85.71 & 0 & 14.29 \\
\hline Eom JS et al. [30] & 71.43 & 0 & 28.57 \\
\hline Feld JJ et al. [31] & 85.71 & 0 & 14.29 \\
\hline Gonzalez-Ochoa AG et al. [32] & 57.14 & 28.57 & 14.29 \\
\hline Gottlieb RL et al. [33] & 85.71 & 0 & 14.29 \\
\hline Gunst GD et al. [34] & 85.71 & 0 & 14.29 \\
\hline Gupta A et al. [35] & 85.71 & 0 & 14.29 \\
\hline Gutierrez-Castrellon P et al. [36] & 71.43 & 0 & 28.57 \\
\hline Humeniuk R et al. [37] & 71.43 & 0 & 28.57 \\
\hline Jagannathan P et al. [38] & 42.86 & 0 & 57.14 \\
\hline Jeronimo CMP et al. [39] & 57.14 & 0 & 42.86 \\
\hline Lenze EJ et al. [40] & 71.43 & 0 & 28.57 \\
\hline López-Medina E et al. [41] & 57.14 & 0 & 42.86 \\
\hline Marconi VC et al. [42] & 85.71 & 0 & 14.29 \\
\hline McCoy J et al. [43] & 57.14 & 0 & 42.86 \\
\hline Mohan A et al. [44] & 57.14 & 0 & 42.86 \\
\hline Monk PD et al. [45] & 71.43 & 0 & 28.57 \\
\hline Omrani AS et al. [46] & 28.57 & 28.57 & 42.86 \\
\hline Patel O et al. [47] & 71.43 & 0 & 28.57 \\
\hline Puskarich MA et al. [48] & 85.71 & 0 & 14.29 \\
\hline
\end{tabular}


Rastogi A et al. [49]

Ravikirti et al. [50]

Reis $\mathrm{G}$ et al. [51]

Rocco PRM et al. [52]

Salama C et al. [53]

Silva M et al. [54]

Sivapalan P et al. [55]

Skipper CP et al. [56]

Stone JH et al. [57]

Tardif JC et al. [58]

Tornling G et al. [59]

Ulrich RJ et al. [60]

Vallejos J et al. [61]

Wang Y et al. [62]

Weinreich DM et al. [63]

CaoY et al. [64]

Cremer PC et al. [65]

de Alencar JCG et al. [66]

Dequin PF et al. [67]

Gharebaghi N et al. [68]

Lescure FX et al. [69]

Libster R et al. [70]

Munch MW et al. [71]

Rosas IO et al. [72]

Sehgal IS et al. [73]

Shi L et al. [74]

Simonovich VA et al. [75]

Sivapalasingam S et al. [76]

Temesgen $\mathrm{Z}$ et al. [77]

Zhong $\mathrm{M}$ et al. [78]
42.86

42.86

57.14

71.43

57.14

57.14

71.43

85.71

71.43

85.71

71.43

71.43

71.43

85.71

71.43

42.86

71.43

71.43

57.14

71.43

85.71

57.14

85.71

85.71

57.14

71.43

42.86

71.43

71.43

57.14
0

0

28.57

0

0

0

14.28

0

0

0

0

0

0

0

0

28.57

0

0

0

0

0

0

0

0

0

0

0

0

0

0
57.14

57.14

14.29

28.57

42.86

42.86

14.29

14.29

28.57

14.29

28.57

28.57

28.57

14.29

28.57

28.57

28.57

28.57

42.86

28.57

14.29

42.86

14.29

14.29

42.86

28.57

57.14

28.57

28.57

42.86 
Supplementary Table 4. Included studies of network meta-analysis for the ratio of virological cure in non-severe patients with COVID-19.

\begin{tabular}{|c|c|c|c|c|}
\hline Study (reference) & $\begin{array}{c}\text { Intervention and } \\
\text { control groups }\end{array}$ & Events & $\mathbf{N}$ & $\begin{array}{c}\text { Ratio of virological } \\
\text { cure }(\%)\end{array}$ \\
\hline Ahmed S et al. 2021 [19] & Ivermectin & 17 & 22 & 77.27 \\
\hline Ahmed S et al. 2021 [19] & Ivermectin/doxycycline & 14 & 23 & 60.87 \\
\hline Ahmed S et al. 2021 [19] & Placebo & 9 & 23 & 39.13 \\
\hline Biber A et al. 2021 [21] & Ivermectin & 39 & 47 & 82.98 \\
\hline Biber A et al. 2021 [21] & Placebo & 25 & 42 & 59.52 \\
\hline Cadegiani FA et al. 2021 [23] & Proxalutamide & 140 & 171 & 81.87 \\
\hline Cadegiani FA et al. 2021 [23] & Placebo & 20 & 65 & 30.77 \\
\hline Chaccour C et al. 2021 [26] & Ivermectin & 1 & 12 & 8.33 \\
\hline Chaccour C et al. 2021 [26] & Placebo & 0.5 & 12 & 4.17 \\
\hline Chen J et al. 2020 [27] & Arbidol & 19 & 23 & 82.61 \\
\hline Chen J et al. 2020 [27] & Placebo & 27 & 35 & 77.14 \\
\hline Devpura G et al. 2021 [28] & Ayurvedic & 45 & 45 & 100.00 \\
\hline Devpura G et al. 2021 [28] & Placebo & 30 & 50 & 60.00 \\
\hline Dubee V et al. 2021 [29] & HCQ & 39 & 91 & 42.86 \\
\hline Dubee V et al. 2021 [29] & Placebo & 36 & 83 & 43.37 \\
\hline Eom JS et al. 2021 [30] & LCP & 93 & 101 & 92.08 \\
\hline Eom JS et al. 2021 [30] & $\mathrm{HCP}$ & 90 & 103 & 87.38 \\
\hline Eom JS et al. 2021 [30] & $\mathrm{CPC}$ & 183 & 204 & 89.71 \\
\hline Eom JS et al. 2021 [30] & Placebo & 86 & 103 & 83.50 \\
\hline Feld JJ et al. 2021 [31] & PL & 24 & 30 & 80.00 \\
\hline Feld JJ et al. 2021 [31] & Placebo & 19 & 30 & 63.33 \\
\hline Gottlieb RL et al. 2021 [33] & LDB & 41 & 85 & 48.24 \\
\hline Gottlieb RL et al. 2021 [33] & MDB & 43 & 93 & 46.24 \\
\hline Gottlieb RL et al. 2021 [33] & HDB & 37 & 86 & 43.02 \\
\hline Gottlieb RL et al. 2021 [33] & MDB/etesevimab & 40 & 82 & 48.78 \\
\hline Gottlieb RL et al. 2021 [33] & Placebo & 56 & 122 & 45.90 \\
\hline Jeronimo CMP et al. 2021 [39] & Methylprednisolone & 91 & 161 & 56.52 \\
\hline Jeronimo CMP et al. 2021 [39] & Placebo & 88 & 157 & 56.05 \\
\hline Mohan A et al. 2020 [44] & Ivermectin & 16 & 36 & 44.44 \\
\hline Mohan A et al. 2020 [44] & Placebo & 14 & 45 & 31.11 \\
\hline Mohan A et al. 2020 [44] & LDI & 13 & 36 & 36.11 \\
\hline Omrani AS et al. 2020 [46] & $\mathrm{HCQ} / \mathrm{AZM}$ & 30 & 149 & 20.13 \\
\hline Omrani AS et al. 2020 [46] & HCQ & 42 & 146 & 28.77 \\
\hline Omrani AS et al. 2020 [46] & Placebo & 45 & 143 & 31.47 \\
\hline Rastogi A et al. 2020 [49] & HDVD & 10 & 16 & 62.50 \\
\hline Rastogi A et al. 2020 [49] & Placebo & 5 & 24 & 20.83 \\
\hline Ravikirti et al. 2021 [50] & Ivermectin & 13 & 55 & 23.64 \\
\hline Ravikirti et al. 2021 [50] & Placebo & 18 & 57 & 31.58 \\
\hline Rocco PRM et al. 2020 [52] & Nitazoxanide & 58 & 194 & 29.90 \\
\hline Rocco PRM et al. 2020 [52] & Placebo & 36 & 198 & 18.18 \\
\hline Silva M et al. 2021 [54] & Nitazoxanide & 14 & 23 & 60.87 \\
\hline Silva M et al. 2021 [54] & Placebo & 7 & 13 & 53.85 \\
\hline Ulrich RJ et al. 2020 [60] & HCQ & 8 & 67 & 11.94 \\
\hline Ulrich RJ et al. 2020 [60] & Placebo & 10 & 61 & 16.39 \\
\hline
\end{tabular}


Vallejos J et al. 2021 [61]

Vallejos J et al. 2021 [61]

Wang Y et al. 2020 [62]

Wang Y et al. 2020 [62]

Weinreich DM et al. 2021 [63]

Weinreich DM et al. 2021 [63]
Ivermectin

Placebo

Remdesivir

Placebo

REGN-COV2

Placebo

$\begin{array}{ccc}212 & 250 & 84.80 \\ 221 & 251 & 88.05 \\ 99 & 131 & 75.57 \\ 54 & 65 & 83.08 \\ 80 & 182 & 43.96 \\ 33 & 93 & 35.48\end{array}$

Abbreviations: COVID-19: coronavirus disease 2019; PL: peginterferon lambda; LDI: low dosage ivermectin; HDVD: high-dose vitamin D; LCP: low dosage CT-P59; HCP: high dosage CT-P59; CPC: CT-P59 combined; HCQ: hydroxychloroquine; AZM: azithromycin; LDB: low dosage bamlanivimab; MDB: moderate dosage bamlanivimab; HDB: high dosage bamlanivimab.

Supplementary Table 5. Included studies of network meta-analysis for all-cause mortality in non-severe patients with COVID-19.

\begin{tabular}{|c|c|c|c|c|}
\hline Study (reference) & $\begin{array}{l}\text { Intervention and } \\
\text { control groups }\end{array}$ & Events & $\mathbf{N}$ & $\begin{array}{c}\text { All-cause } \\
\text { mortality }(\%)\end{array}$ \\
\hline ACTIV-3/TICO LY-CoV555 Study Group 2021 [18] & LY-CoV555 & 9 & 163 & 5.52 \\
\hline ACTIV-3/TICO LY-CoV555 Study Group 2021 [18] & Placebo & 5 & 151 & 3.31 \\
\hline Aman J et al. 2021 [20] & Imatinib & 15 & 197 & 7.61 \\
\hline Aman J et al. 2021 [20] & Placebo & 27 & 188 & 14.36 \\
\hline Blum VF et al. 2021 [22] & Nitazoxanide & 2 & 25 & 8.00 \\
\hline Blum VF et al. 2021 [22] & Placebo & 6 & 25 & 24.00 \\
\hline Cadegiani FA et al. 2021 [24] & Proxalutamide & 35 & 317 & 11.04 \\
\hline Cadegiani FA et al. 2021 [24] & Placebo & 162 & 328 & 49.39 \\
\hline Caricchio R et al. 2021 [25] & Canakinumab & 11 & 223 & 4.93 \\
\hline Caricchio R et al. 2021 [25] & Placebo & 16 & 222 & 7.21 \\
\hline Dubee V et al. 2021 [29] & HCQ & 6 & 124 & 4.84 \\
\hline Dubee V et al. 2021 [29] & Placebo & 11 & 123 & 8.94 \\
\hline Eom JS et al. 2021 [30] & LCP & 0 & 95 & 87.37 \\
\hline Eom JS et al. 2021 [30] & $\mathrm{HCP}$ & 0 & 92 & 85.87 \\
\hline Eom JS et al. 2021 [30] & $\mathrm{CPC}$ & 0 & 187 & 86.63 \\
\hline Eom JS et al. 2021 [30] & Placebo & 0 & 98 & 71.43 \\
\hline Gonzalez-Ochoa AG et al. 2021 [32] & Sulodexide & 3 & 124 & 2.42 \\
\hline Gonzalez-Ochoa AG et al. 2021 [32] & Placebo & 7 & 119 & 5.88 \\
\hline Gunst GD et al. 2021 [34] & Camostat-mesilate & 8 & 137 & 5.84 \\
\hline Gunst GD et al. 2021 [34] & Placebo & 4 & 68 & 5.88 \\
\hline Gupta A et al. 2021 [35] & Sotrovimab & 0 & 291 & 0 \\
\hline Gupta A et al. 2021 [35] & Placebo & 1 & 292 & 0.34 \\
\hline Gutierrez-Castrellon P et al. 2021 [36] & NPF & 0 & 150 & 0 \\
\hline Gutierrez-Castrellon P et al. 2021 [36] & Placebo & 0 & 150 & 0 \\
\hline Jeronimo CMP et al. 2021 [39] & Methylprednisolone & 72 & 194 & 37.11 \\
\hline Jeronimo CMP et al. 2021 [39] & Placebo & 76 & 199 & 38.19 \\
\hline López-Medina E et al. 2021 [41] & Ivermectin & 0 & 200 & 0 \\
\hline López-Medina E et al. 2021 [41] & Placebo & 1 & 198 & 0.51 \\
\hline Marconi VC et al. 2021 [42] & Baricitinib & 62 & 764 & 8.12 \\
\hline Marconi VC et al. 2021 [42] & Placebo & 100 & 761 & 13.14 \\
\hline McCoy J et al. 2021 [43] & Proxalutamide & 0 & 134 & 0 \\
\hline McCoy J et al. 2021 [43] & Placebo & 2 & 128 & 1.56 \\
\hline Monk PD et al. 2020 [45] & IFN- $\beta$ & 0 & 50 & 0.00 \\
\hline
\end{tabular}


Monk PD et al. 2020 [45]

Patel O et al. 2021 [47]

Patel O et al. 2021 [47]

Puskarich MA et al. 2021 [48]

Puskarich MA et al. 2021 [48]

Ravikirti et al. 2021 [50]

Ravikirti et al. 2021 [50]

Salama C et al. 2021 [53]

Salama C et al. 2021 [53]

Silva M et al. 2021 [54]

Silva M et al. 2021 [54]

Sivapalan P et al. 2021 [55]

Sivapalan P et al. 2021 [55]

Skipper CP et al. 2020 [56]

Skipper CP et al. 2020 [56]

Stone JH et al. 2020 [57]

Stone JH et al. 2020 [57]

Tardif JC et al. 2021 [58]

Tardif JC et al. 2021 [58]

Tornling G et al. 2021 [59]

Tornling G et al. 2021 [59]

Ulrich RJ et al. 2020 [60]

Ulrich RJ et al. 2020 [60]

Vallejos J et al. 2021 [61]

Vallejos J et al. 2021 [61]

Wang Y et al. 2020 [62]

Wang Y et al. 2020 [62]

\begin{tabular}{|c|c|c|c|}
\hline Placebo & 3 & 51 & 5.88 \\
\hline HDIVZn & 2 & 15 & 13.33 \\
\hline Placebo & 3 & 18 & 16.67 \\
\hline Losartan & 0 & 58 & 0 \\
\hline Placebo & 0 & 59 & 0 \\
\hline Ivermectin & 0 & 55 & 0 \\
\hline Placebo & 4 & 57 & 7.02 \\
\hline Tocilizumab & 26 & 249 & 10.44 \\
\hline Placebo & 11 & 128 & 8.59 \\
\hline Nitazoxanide & 1 & 27 & 3.70 \\
\hline Placebo & 1 & 13 & 7.69 \\
\hline HCQ/AZM & 9 & 61 & 14.75 \\
\hline Placebo & 6 & 56 & 10.71 \\
\hline HCQ & 1 & 212 & 0.47 \\
\hline Placebo & 1 & 211 & 0.47 \\
\hline Tocilizumab & 9 & 161 & 5.59 \\
\hline Placebo & 4 & 82 & 4.88 \\
\hline Colchicine & 5 & 2235 & 0.22 \\
\hline Placebo & 9 & 2253 & 0.40 \\
\hline $\mathrm{C} 21$ & 1 & 51 & 1.96 \\
\hline Placebo & 3 & 55 & 5.45 \\
\hline HCQ & 7 & 67 & 10.45 \\
\hline Placebo & 6 & 61 & 9.84 \\
\hline Ivermectin & 4 & 250 & 1.60 \\
\hline Placebo & 3 & 251 & 1.20 \\
\hline Remdesivir & 22 & 150 & 14.67 \\
\hline Placebo & 10 & 77 & 12.99 \\
\hline
\end{tabular}

Abbreviations: COVID-19: coronavirus disease 2019; LCP: low dosage CT-P59 (i.e., a monoclonal antibody with potent neutralizing activity); HCP: high dosage CT-P59; CPC: CT-P59 combined; HCQ: hydroxychloroquine; AZM: azithromycin; HDIVZn: high-dose intravenous zinc; IFN- $\beta$ : interferon beta; NPF: novel probiotic formulation. 
Supplementary Table 6. Included studies of network meta-analysis for treatment-emergent adverse events in nonsevere patients with COVID-19.

\begin{tabular}{|c|c|c|c|c|}
\hline Study (reference) & $\begin{array}{l}\text { Intervention and } \\
\text { control groups }\end{array}$ & Events & $\mathbf{N}$ & $\begin{array}{l}\text { Ratio of treatment- } \\
\text { emergent adverse } \\
\text { events }(\%)\end{array}$ \\
\hline ACTIV-3/TICO LY-CoV555 Study Group 2021 [18] & LY-CoV555 & 38 & 163 & 23.31 \\
\hline ACTIV-3/TICO LY-CoV555 Study Group 2021 [18] & Placebo & 30 & 151 & 19.87 \\
\hline Biber A et al. 2021 [21] & Ivermectin & 2 & 47 & 4.26 \\
\hline Biber A et al. 2021 [21] & Placebo & 3 & 42 & 7.14 \\
\hline Blum VF et al. 2021 [22] & Nitazoxanide & 8 & 25 & 32.00 \\
\hline Blum VF et al. 2021 [22] & Placebo & 13 & 25 & 52.00 \\
\hline Cadegiani FA et al. 2021 [24] & Proxalutamide & 109 & 317 & 34.38 \\
\hline Cadegiani FA et al. 2021 [24] & Placebo & 225 & 328 & 68.60 \\
\hline Chaccour C et al. 2021 [26] & Ivermectin & 5 & 12 & 41.67 \\
\hline Chaccour C et al. 2021 [26] & Placebo & 5 & 12 & 41.67 \\
\hline Chen J et al. 2020 [27] & $\mathrm{LPV} / \mathrm{r}$ & 9 & 52 & 17.31 \\
\hline Chen J et al. 2020 [27] & Arbidol & 3 & 34 & 8.82 \\
\hline Chen J et al. 2020 [27] & Placebo & 4 & 48 & 8.33 \\
\hline Dubee V et al. 2021 [29] & HCQ & 2 & 124 & 1.61 \\
\hline Dubee V et al. 2021 [29] & Placebo & 2 & 123 & 1.63 \\
\hline Eom JS et al. 2021 [30] & LCP & 31 & 105 & 29.52 \\
\hline Eom JS et al. 2021 [30] & $\mathrm{HCP}$ & 27 & 110 & 24.55 \\
\hline Eom JS et al. 2021 [30] & Placebo & 34 & 110 & 30.91 \\
\hline Feld JJ et al. 2021 [31] & PL & 2 & 30 & 6.67 \\
\hline Feld JJ et al. 2021 [31] & Placebo & 1 & 30 & 3.33 \\
\hline Gonzalez-Ochoa AG et al. 2021 [32] & Sulodexide & 96 & 124 & 77.42 \\
\hline Gonzalez-Ochoa AG et al. 2021 [32] & Placebo & 85 & 119 & 71.43 \\
\hline Gottlieb RL et al. 2021 [33] & LDB & 27 & 101 & 26.73 \\
\hline Gottlieb RL et al. 2021 [33] & MDB & 26 & 107 & 24.30 \\
\hline Gottlieb RL et al. 2021 [33] & HDB & 22 & 101 & 21.78 \\
\hline Gottlieb RL et al. 2021 [33] & MDB/etesevimab & 19 & 112 & 16.96 \\
\hline Gottlieb RL et al. 2021 [33] & Placebo & 42 & 156 & 26.92 \\
\hline Gunst GD et al. 2021 [34] & Camostat-mesilate & 53 & 137 & 38.69 \\
\hline Gunst GD et al. 2021 [34] & Placebo & 35 & 68 & 51.47 \\
\hline Gupta A et al. 2021 [35] & Sotrovimab & 73 & 430 & 16.98 \\
\hline Gupta A et al. 2021 [35] & Placebo & 85 & 438 & 19.41 \\
\hline Gutierrez-Castrellon P et al. 2021 [36] & NPF & 41 & 150 & 27.33 \\
\hline Gutierrez-Castrellon P et al. 2021 [36] & Placebo & 63 & 150 & 42.00 \\
\hline Humeniuk R et al. 2020 [37] & Remdesivir & 17 & 78 & 21.79 \\
\hline Humeniuk R et al. 2020 [37] & Placebo & 2 & 18 & 11.11 \\
\hline Jagannathan P et al. 2021 [38] & PL & 36 & 60 & 60.00 \\
\hline Jagannathan P et al. 2021 [38] & Placebo & 30 & 60 & 50.00 \\
\hline Lenze EJ et al. 2020 [40] & Fluvoxamine & 12 & 80 & 15.00 \\
\hline Lenze EJ et al. 2020 [40] & Placebo & 11 & 72 & 15.28 \\
\hline López-Medina E et al. 2021 [41] & Ivermectin & 154 & 200 & 77.00 \\
\hline López-Medina E et al. 2021 [41] & Placebo & 161 & 198 & 81.31 \\
\hline Marconi VC et al. 2021 [42] & Baricitinib & 334 & 750 & 44.53 \\
\hline Marconi VC et al. 2021 [42] & Placebo & 334 & 752 & 44.41 \\
\hline
\end{tabular}


McCoy J et al. 2021 [43]

McCoy J et al. 2021 [43]

Mohan A et al. 2020 [44]

Mohan A et al. 2020 [44]

Mohan A et al. 2020 [45]

Monk PD et al. 2020 [45]

Monk PD et al. 2020 [45]

Reis G et al. 2021 [51]

Reis G et al. 2021 [51]

Reis G et al. 2021 [51]

Rocco PRM et al. 2020 [52]

Rocco PRM et al. 2020 [52]

Salama C et al. 2021 [53]

Salama C et al. 2021 [53]

Silva M et al. 2021 [54]

Silva M et al. 2021 [54]

Skipper CP et al. 2020 [56]

Skipper CP et al. 2020 [56]

Stone JH et al. 2020 [57]

Stone JH et al. 2020 [57]

Tardif JC et al. 2021 [58]

Tardif JC et al. 2021 [58]

Ulrich RJ et al. 2020 [60]

Ulrich RJ et al. 2020 [60]

Vallejos J et al. 2021 [61]

Vallejos J et al. 2021 [61]

Wang Y et al. 2020 [62]

Wang Y et al. 2020 [62]

Weinreich DM et al. 2021 [63]

Weinreich DM et al. 2021 [63]

\begin{tabular}{|c|c|c|c|}
\hline Proxalutamide & 82 & 134 & 61.19 \\
\hline Placebo & 116 & 128 & 90.63 \\
\hline Ivermectin & 6 & 51 & 11.76 \\
\hline LDI & 8 & 49 & 16.33 \\
\hline Placebo & 6 & 52 & 11.54 \\
\hline IFN- $\beta$ & 26 & 48 & 54.17 \\
\hline Placebo & 30 & 50 & 60.00 \\
\hline HCQ & 46 & 207 & 22.22 \\
\hline $\mathrm{LPV} / \mathrm{r}$ & 92 & 232 & 39.66 \\
\hline Placebo & 46 & 220 & 20.91 \\
\hline Nitazoxanide & 60 & 194 & 30.93 \\
\hline Placebo & 60 & 198 & 30.30 \\
\hline Tocilizumab & 127 & 250 & 50.80 \\
\hline Placebo & 67 & 127 & 52.76 \\
\hline Nitazoxanide & 7 & 27 & 25.93 \\
\hline Placebo & 2 & 13 & 15.38 \\
\hline HCQ & 92 & 212 & 43.40 \\
\hline Placebo & 46 & 211 & 21.80 \\
\hline Tocilizumab & 80 & 161 & 49.69 \\
\hline Placebo & 46 & 82 & 56.10 \\
\hline Colchicine & 108 & 2195 & 4.92 \\
\hline Placebo & 139 & 2217 & 6.27 \\
\hline HCQ & 38 & 67 & 56.72 \\
\hline Placebo & 36 & 61 & 59.02 \\
\hline Ivermectin & 45 & 250 & 18.00 \\
\hline Placebo & 53 & 251 & 21.12 \\
\hline Remdesivir & 102 & 155 & 65.81 \\
\hline Placebo & 50 & 78 & 64.10 \\
\hline REGN-COV2 & 5 & 176 & 2.84 \\
\hline Placebo & 7 & 93 & 7.53 \\
\hline
\end{tabular}

Abbreviations: COVID-19: coronavirus disease 2019; LPV/r: lopinavir-ritonavir; PL: peginterferon lambda; LDI: low dosage ivermectin; LCP: low dosage CT-P59 (i.e., a monoclonal antibody with potent neutralizing activity); HCP: high dosage CT-P59; HCQ: hydroxychloroquine; LDB: low dosage bamlanivimab; MDB: moderate dosage bamlanivimab; HDB: high dosage bamlanivimab; IFN- $\beta$ : interferon beta; NPF: novel probiotic formulation. 
Supplementary Table 7. Included studies of network meta-analysis for all-cause mortality in severe patients with COVID-19.

\begin{tabular}{|c|c|c|c|c|}
\hline Study (reference) & $\begin{array}{c}\text { Intervention and control } \\
\text { groups }\end{array}$ & Events & $\mathbf{N}$ & $\begin{array}{c}\text { All-cause } \\
\text { mortality }(\%)\end{array}$ \\
\hline CaoY et al. 2021 [64] & Ruxolitinib & 0 & 20 & 0.00 \\
\hline CaoY et al. 2021 [64] & Placebo & 3 & 21 & 14.29 \\
\hline Cremer PC et al. 2021 [65] & Mavrilimumab & 1 & 21 & 4.76 \\
\hline Cremer PC et al. 2021 [65] & Placebo & 3 & 19 & 15.79 \\
\hline de Alencar JCG et al. 2021 [66] & $\mathrm{N}$-acetylcysteine & 9 & 67 & 13.43 \\
\hline de Alencar JCG et al. 2021 [66] & Placebo & 9 & 68 & 13.24 \\
\hline Dequin PF et al. 2020 [67] & Hydrocortisone & 11 & 76 & 14.47 \\
\hline Dequin PF et al. 2020 [67] & Placebo & 20 & 73 & 27.40 \\
\hline Gharebaghi $\mathrm{N}$ et al. 2020 [68] & IG & 6 & 30 & 20.00 \\
\hline Gharebaghi $\mathrm{N}$ et al. 2020 [68] & Placebo & 14 & 29 & 48.28 \\
\hline Lescure FX et al. 2021 [69] & Placebo & 7 & 84 & 8.33 \\
\hline Lescure FX et al. 2021 [69] & LS & 16 & 159 & 10.06 \\
\hline Lescure FX et al. 2021 [69] & HS & 14 & 173 & 8.09 \\
\hline Libster R et al. 2021 [70] & $\mathrm{CP}$ & 2 & 80 & 2.50 \\
\hline Libster R et al. 2021 [70] & Placebo & 4 & 80 & 5.00 \\
\hline Munch MW et al. 2021 [71] & Hydrocortisone & 6 & 16 & 37.50 \\
\hline Munch MW et al. 2021 [71] & Placebo & 2 & 14 & 14.29 \\
\hline Rosas IO et al. 2021 [72] & Tocilizumab & 58 & 294 & 19.73 \\
\hline Rosas IO et al. 2021 [72] & Placebo & 28 & 144 & 19.44 \\
\hline Sehgal IS et al. 2021 [73] & Mycobacterium-w & 4 & 20 & 20.00 \\
\hline Sehgal IS et al. 2021 [73] & Placebo & 5 & 22 & 22.73 \\
\hline Simonovich VA et al. 2020 [75] & $\mathrm{CP}$ & 25 & 228 & 10.96 \\
\hline Simonovich VA et al. 2020 [75] & Placebo & 12 & 105 & 11.43 \\
\hline Sivapalasingam S et al. 2021 [76] & LS & 60 & 242 & 24.79 \\
\hline Sivapalasingam S et al. 2021 [76] & HS & 103 & 338 & 30.47 \\
\hline Sivapalasingam S et al. 2021 [76] & Placebo & 43 & 170 & 25.29 \\
\hline Temesgen Z et al. 2021 [77] & Lenzilumab & 23 & 236 & 9.75 \\
\hline Temesgen Z et al. 2021 [77] & Placebo & 34 & 243 & 13.99 \\
\hline Zhong M et al. 2020 [78] & ALA & 3 & 8 & 37.50 \\
\hline Zhong M et al. 2020 [78] & Placebo & 7 & 9 & 77.78 \\
\hline
\end{tabular}

Abbreviations: COVID-19: coronavirus disease 2019; CP: convalescent plasma; ALA: $\alpha$-Lipoic acid; LS: low dosage sarilumab; HS: high dosage sarilumab; IG: immunoglobulin gamma. 
Supplementary Table 8. Included studies of network meta-analysis for treatment-emergent adverse events in severe patients with COVID-19.

\begin{tabular}{llccc}
\hline \multicolumn{1}{c}{ Study (reference) } & $\begin{array}{c}\text { Intervention and } \\
\text { control groups }\end{array}$ & Events & N & $\begin{array}{c}\text { Ratio of treatment-emergent } \\
\text { adverse events (\%) }\end{array}$ \\
\hline CaoY et al. 2021 [64] & Ruxolitinib & 7 & 20 & 35.00 \\
CaoY et al. 2021 [64] & Placebo & 6 & 21 & 28.57 \\
Lescure FX et al. 2021 [69] & LS & 103 & 159 & 64.78 \\
Lescure FX et al. 2021 [69] & HS & 121 & 173 & 69.94 \\
Lescure FX et al. 2021 [69] & Placebo & 55 & 84 & 65.48 \\
Rosas IO et al. 2021 [72] & Tocilizumab & 228 & 295 & 77.29 \\
Rosas IO et al. 2021 [72] & Placebo & 116 & 143 & 81.12 \\
Sehgal IS et al. 2021 [73] & Mycobacterium-w & 0 & 20 & 0.00 \\
Sehgal IS et al. 2021 [73] & Placebo & 0 & 22 & 0.00 \\
Shi L et al. 2021 [74] & UC-MSCs & 37 & 65 & 56.92 \\
Shi L et al. 2021 [74] & Placebo & 21 & 35 & 60.00 \\
Simonovich VA et al. 2020 [75] & CP & 153 & 228 & 67.11 \\
Simonovich VA et al. 2020 [75] & Placebo & 66 & 105 & 62.86 \\
Sivapalasingam S et al. 2021 [76] & LS & 19 & 50 & 38.00 \\
Sivapalasingam S et al. 2021 [76] & HS & 25 & 51 & 49.02 \\
Sivapalasingam S et al. 2021 [76] & Placebo & 7 & 25 & 28.00 \\
Temesgen Z et al. 2021 [77] & Lenzilumab & 68 & 255 & 26.67 \\
Temesgen Z et al. 2021 [77] & Placebo & 84 & 257 & 32.68 \\
\hline
\end{tabular}

Abbreviations: COVID-19: coronavirus disease 2019; CP: convalescent plasma; LS: low dosage sarilumab; HS: high dosage sarilumab. 
Supplementary Table 9. Assessment of incoherence for each outcome from the node-splitting model.

Evaluation of inconsistency using loop-specific heterogeneity estimates: A

\begin{tabular}{ccccccc}
\hline Loop & IF & SeIF & $z_{\text {_value }}$ & $\boldsymbol{p}$ _value & CI_95 & Loop_Heterog_tau2 \\
\hline $09-10-19$ & 1.453 & 1.212 & 1.199 & 0.231 & $(0.00,3.83)$ & 0.277 \\
$09-13-19$ & 0.132 & 1.356 & 0.098 & 0.922 & $(0.00,2.79)$ & 0.595 \\
$05-06-19$ & 0.015 & 0.467 & 0.033 & 0.974 & $(0.00,0.93)$ & 0.000 \\
$03-04-11$ & - & - & - & - & 0.000 \\
$03-04-19$ & - & - & - & - & - & 0.000 \\
$07-12-19$ & - & - & - & - & - & 0.000 \\
$07-15-19$ & - & - & - & - & 0.000 \\
$07-14-15$ & - & - & - & - & 0.000 \\
$07-14-19$ & - & - & - & - & 0.000 \\
$07-12-15$ & - & - & - & - & - & 0.000 \\
$12-14-15$ & - & - & - & - & 0.000 \\
$12-15-19$ & - & - & - & - & 0.000 \\
$12-14-19$ & - & - & - & - & 0.000 \\
$03-11-19$ & - & - & - & - & 0.000 \\
$07-11-19$ & -14 & - & - & - & & 0.000 \\
\hline
\end{tabular}

A. The ratio of virological cure for non-severe COVID-19 patients (03: CT-P59 combined high dosage CT-P59; 05: hydroxychloroquine; 06: hydroxychloroquine/azithromycin; 07 high dosage bamlanivimab; 09: ivermectin; 10: ivermectin/ doxycycline; 11: low dosage CT-P59; 12: low dosage bamlanivimab; 13: low dosage ivermectin; 14: moderate dosage bamlanivimab; 15: moderate dosage bamlanivimab/etesevimab; 19: placebo).

Evaluation of inconsistency using loop-specific heterogeneity estimates: B

\begin{tabular}{|c|c|c|c|c|c|c|}
\hline Loop & IF & seIF & $z$ _value & p_value & CI_95 & Loop_Heterog_tau2 \\
\hline 03-07-14 & - & - & - & - & & 0.000 \\
\hline 03-14-20 & - & - & - & - & & 0.000 \\
\hline 03-07-20 & - & - & - & - & & 0.000 \\
\hline 07-14-20 & - & - & - & - & & 0.000 \\
\hline
\end{tabular}

B. All-cause mortality for non-severe COVID-19 patients (03: CT-P59 combined; 07: high dosage CT-P59 ; 14: low dosage CTP59; 20: placebo).

Evaluation of inconsistency using loop-specific heterogeneity estimates: C

\begin{tabular}{ccccccc}
\hline Loop & IF & seIF & $\boldsymbol{z}_{\text {_value }}$ & $\boldsymbol{p}$ _value & CI_95 & Loop_Heterog_tau2 \\
\hline $07-14-21$ & 0.407 & 0.814 & 0.500 & 0.617 & $(0.00,2.00)$ & 0.258 \\
$10-13-21$ & 0.250 & 0.838 & 0.299 & 0.765 & $(0.00,1.89)$ & 0.000 \\
$01-14-21$ & 0.077 & 1.088 & 0.070 & 0.944 & $(0.00,2.21)$ & 0.000 \\
$08-12-17$ & - & - & - & - & 0.000 \\
$08-12-21$ & - & - & - & - & - & 0.000 \\
$08-12-16$ & - & - & - & - & - & 0.000 \\
$08-16-17$ & - & - & - & - & 0.000 \\
$08-16-21$ & - & - & - & - & 0.000 \\
$12-16-21$ & - & - & - & - & 0.000 \\
$08-17-21$ & - & - & - & & 0.000 \\
$12-16-17$ & - & - & - & & 0.000 \\
\hline
\end{tabular}

C. The ratio of treatment-emergent adverse events for non-severe COVID-19 patients (01: arbidol; 07: high dosage CT-P59; 08: hydroxychloroquine; 10: interferon beta; 12: low dosage CT-P59; 13: low dosage bamlanivimab; 14: low dosage ivermectin; 16: LY-CoV555; 17: moderate dosage bamlanivimab; 21: peginterferon lambda). 
Evaluation of inconsistency using loop-specific heterogeneity estimates: D

\begin{tabular}{ccccccc}
\hline Loop & IF & seIF & $z_{-}$value & p_value & CI_95 & Loop_Heterog_tau2 \\
\hline $03-06-11$ & - & - & - & - & 0.000 \\
\hline
\end{tabular}

D. All-cause mortality of severe COVID-19 patients (03: high dosage sarilumab; 06: low dosage sarilumab; 11: placebo).

Evaluation of inconsistency using loop-specific heterogeneity estimates: $E$

\begin{tabular}{|c|c|c|c|c|c|c|}
\hline Loop & IF & SeIF & $z_{-}$value & p_value & CI_95 & Loop_Heterog_tau2 \\
\hline $2-3-6$ & - & - & - & - & & 0.000 \\
\hline
\end{tabular}

E. The ratio of treatment-emergent adverse events in severe COVID-19 patients (2: high dosage sarilumab; 3: low dosage sarilumab; 6: placebo).

Appendix 1. See Appendix 1

Appendix 2. See Appendix 2 